\title{
Forebrain Origins and Terminations of the Medial Forebrain Bundle Metabolically Activated by Rewarding Stimulation or by Reward- blocking Doses of Pimozide'
}

\author{
C. R. GALlistel, ${ }^{2}$ Y. GOMITA, ${ }^{3}$ ELNA YADIN, ${ }^{4}$ AND KENNETH A. CAMPBELL ${ }^{5}$ \\ Department of Psychology, University of Pennsylvania, Philadelphia, Pennsylvania 19104
}

\begin{abstract}
Using $\left[{ }^{14} \mathrm{C}\right]-2$-deoxyglucose autoradiography, we determined which forebrain and diencephalic areas showed metabolic alterations in response to unilateral electrical stimulation of the posterior medial forebrain bundle at parameters chosen to produce a just-submaximal rewarding effect. At these parameters, only a few areas were activated. There was no detectable activation anterior or dorsal to the genu of the corpus callosum. Just anterior to the anterior commissure, there was strong activation of the vertical limb of the diagonal band of Broca, with a focus in the nucleus of the diagonal band. Just posterior to the anterior commissure, there was strong activation of compartment " $c$ " of the medial forebrain bundle (MFB), with weaker activation of the bed nucleus of the stria terminalis and the medial preoptic area. At midhypothalamic levels, the dorsolateral, dorsomedial, and ventral MFB all showed activation. There was bilateral suppression of activity in the lateral habenula. Activation appeared to end in the anterior ventral tegmental area of Tsai. Reward-blocking doses of the neuroleptic pimozide activated the caudate and the lateral habenula but did not alter any of the unilateral effects of stimulation. Using longer pulse durations and/or shifting the site of stimulation to the substantia nigra activated many of the systems not activated in the first experiment, including all of the major dopaminergic projection systems, proving the capacity of the technique to reveal activation of these systems. The results permit one to define a discrete projection system that merits electrophys-
\end{abstract}

Received August 13, 1984; Revised December 6, 1984;

Accepted December 7, 1984

${ }^{1}$ This work was supported by National Science Foundation Grant BNS 82 11972 to C. R. G.; image processing was supported by National Institutes of Health Biotechnology Resource Center Grant 23-1352630. K. A. C. was supported on a postdoctoral fellowship from National Institute for Mental Health Training Grant T32 MH15092. This report was partially prepared while C. R. G. was a Fellow at the Center for Advanced Study in the Behavioral Sciences; partial support there by the Alfred P. Sloan Foundation is gratefully acknowledged.

${ }^{2}$ To whom correspondence should be directed, at: Center for Advanced Study in the Behavioral Sciences, 202 Junipero Serra Blvd, Stanford, CA 94305.

${ }^{3}$ Present address: Daiichi College of Pharmaceutical Sciences, 93 Tamagawa-Cho, Minami-ku, Fukuoka, 815, Japan.

${ }^{4}$ Present address: Department of Psychology, Bryn Mawr College, Bryn Mawr, PA 19010.

${ }^{5}$ Present address: Department of Physiology, Bowman-Gray School of Medicine, Winston-Salem, NC 27103. iological investigation as a likely substrate for the rewarding effect of MFB stimulation. They also suggest that dopaminergic projection systems may not form part of the reward pathway itself.

Behavioral experiments, using methods for determining quantitative properties of the neural substrate, have led to the conclusion that the directly stimulated substrate for electrical self-stimulation of the medial forebrain bundle (MFB) is comprised in substantial part of long, thin myelinated axons descending from forebrain nuclei to the anterior ventral tegmentum (C. Bielajew and P. Shizgal, manuscript submitted for publication; Gallistel et al., 1981). The detailed quantitative information from these new behavioral methods makes it reasonable to use microelectrode recording methods in a search for the somata of axons that course in the MFB and possess the requisite quantitative properties (refractory periods, conduction velocities, strength-duration characteristics). However, on anatomical grounds, as many as 50 distinct projection systems may be recog nized in the MFB (Nieuwenhuys et al., 1982). One wants, if possible, to narrow the field of search at first to those areas where there is a high density of activated tissue. Autoradiography using the metabolic marker $\left[{ }^{14} \mathrm{C}\right.$-2-deoxyglucose (2DG; Sokoloff et al., 1977) seems ideally suited to delimiting those areas where the search should be concentrated. In order to activate as few extraneous systems as possible, it is advisable to choose the parameters of stimulation just strong enough to produce a substantial rewarding effect, and no stronger. In this paper, we report a survey of the forebrain areas metabolically activated by rewarding stimulation of the posterior MFB, with the magnitude of the stimulation chosen to yield a justsubmaximal rewarding effect.

While the directly stimulated axons responsible for the rewarding effect appear to be predominantly myelinated descending fibers (therefore, not catecholaminergic), there is nonetheless extensive pharmacological evidence that neuroleptics attenuate the rewarding efficacy of stimulation (Liebman and Butcher, 1974; Fouriezos and Wise, 1976; Franklin, 1978; Gallistel et al., 1982a; Gallistel and Karras, 1984). Their potency in blocking the rewarding effect of stimulation is predicted by their affinity for the dopamine $\mathrm{D}_{2}$ receptor (Gallistel and Davis, 1983). This has led to the conjecture that one or another ascending dopaminergic projection may form a subsequent stage in the reward pathway (Wise, 1980). Ascending dopamine projections have also been implicated in the reinforcing properties of psychomotor stimulants (cocaine, amphetamine) and opiates (Yokel and Wise, 1975; Roberts et al., 1977; Pickens et al; 1978; Lyness et al., 1979; Hoebel, 1984), which has led to the suggestion that one of the ascending dopaminergic projection systems, most probably the mesolimbic projection, is a final common path for rewarding effects of all kinds (Wise, 1982). Therefore, we also examined the effects of reward-blocking doses of the neuroleptic pimozide. 
In experiment I, five groups of subjects were used to assess the metabolic effects of rewarding MFB stimulation and of rewardblocking doses of pimozide: (1) an unstimulated, undrugged control group (C group); (2) a self-stimulating group (SS); (3) a group that received experimenter-administered stimulation but no drug (OS); (4) a group that received the drug and experimenter-administered rewarding stimulation (PS); and (5) a group that received only the drug (PO).

Many MFB projection systems were not activated by the stimulation in this first experiment; most notably, none of the ascending dopamine projection systems. This negative result raises the question of whether the activation of these other systems is susceptible to visualization by 2DG autoradiography. In experiment II, we show that when other parameters or sites of stimulation are employed, these other systems, and particularly the dopaminergic projection systems, show clear autoradiographic activation. Since these systems were not activated in the first experiment, we assume that they are not part of the directly stimulated reward pathway. Whether they may function as a postsynaptic stage in the reward pathway is taken up under "General Discussion."

\section{Experiment I}

\section{Methods}

\section{Subjects}

Subjects were 25 male albino rats of the Sprague-Dawley strain (Charles River), weighing 225 to $531 \mathrm{gm}$ at the time of implantation and 320 to 550 $\mathrm{gm}$ at the time of 2DG injection and sacrifice. Twenty-one were implanted with monopolar stainless steel electrodes $(0.25 \mathrm{~mm}$; Formvar insulated) in the right posterior MFB (coordinates: $4.0 \mathrm{~mm}$ posterior to bregma, $1.4 \mathrm{~mm}$ lateral, and 8.5 to $9.0 \mathrm{~mm}$ below level skull surface). During sectioning of the brains, all stimulating electrodes were verified to be in the posterior MFB or anterior ventral tegmentum, at the level of plates 38 to 45 in the atlas of Konig and Klippel (1967). Five animals were assigned to each of the five groups. Subjects receiving rewarding stimulation during isotope uptake were chosen from a larger population of implanted animals because they learned to self-stimulate within one half-hour session. Four of the control animals also had electrodes. Of the five animals receiving only pimozide, two had electrodes and three did not.

\section{Apparatus}

Animals were tested in a Skinner box, $26 \mathrm{~cm}$ on a side and $46 \mathrm{~cm}$ high with a hardware cloth floor. Each press on the lever yielded a train of constant-current cathodal pulses. The current and the voltage across the rat were monitored on a differential oscillosope. An electronic switch shunted the stimulating electrode to the indifferent electrode between pulses, to prevent electrode polarization.

\section{Procedure}

Choice of stimulating parameters. The fixed parameters of stimulation were train duration $(0.5 \mathrm{sec})$, pulse duration $(0.1 \mathrm{msec})$, and pulse frequency (100 pulses per sec). The current intensity used during the 2DG-uptake session was the current that produced a rate of pressing equal to $75 \%$ of the animal's maximal rate. Rate-intensity functions were determined by varying the current every 2 min and counting the number of presses in the second min following each change. The current settings were chosen pseudorandomly from a sequence of eight values, spaced 0.1 log unit apart $(80,100,126,160,200, \ldots \mu \mathrm{A})$. The function was determined repeatedly until the current estimated to produce a rate $75 \%$ of the maximum did not differ by more than $0.1 \log$ unit from one determination to the next.

Animals were assigned to groups in such a way as to approximately equate the currents used. Rats in the self-stimulating (SS) group were paired with rats in the PS group, so that current intensity did not differ by more than $20 \%$ within a pair. The SS rats were run first. In the two groups receiving experimenter-administered stimulation (OS and PS), each rat was yoked to a rat in the self-stimulation group; for a OS or PS rat, the number of trains per min administered during the 2DG session was determined by the average rate of self-administration in the SS rat to which it was yoked. The currents employed ranged from 125 to $403 \mu \mathrm{A}$, and the rate of train delivery during uptake ranged from 43 to $110 / \mathrm{min}$.

Autoradiography. On the day of autoradiography, rats in the two groups treated with pimozide were given injections of $0.75 \mathrm{mg} / \mathrm{kg}$ of pimozide-a reward-blocking dose (Gallistel et al., 1982a) $-4 \mathrm{hr}$ before the start of the uptake session. Rats in the other three groups were given injections of the vehicle $(0.3 \%$ tartaric acid). At the start of the uptake session, rats were placed in the test boxes. The self-stimulating rats began self-delivering stimulation immediately. Stimulation was administered automatically to the rals in the other stirnulated groups, starting with their placement in the box. Rats in the unstimulated groups were simply placed in the box. Five minutes after placement in the test box, all rats were given injections of $30 \mu \mathrm{Ci}$ of $\left[{ }^{14} \mathrm{C}\right] 2 \mathrm{DG}$, i.p. In the stimulated groups, stimulation resumed immediately after injection and continued for $45 \mathrm{~min}$; the unstimulated rats remained in the test box during this 45-min uptake period.

At the end of the uptake period, the rats were anesthetized with Chloropent ( $2 \mathrm{ml}$, i.p.) and perfused intracardially for $30 \mathrm{sec}$ with $3.3 \%$ formalin buffered to $\mathrm{a} \mathrm{pH}$ of 7.4. The brains were removed and immersed in liquid Freon chilled with dry ice to $-55^{\circ} \mathrm{C}$. The frozen brains were sectioned on a Slee cryostat at $-18^{\circ} \mathrm{C}$. Every 10 th section was placed on a coverslip and dried rapidly on a warming tray at $60^{\circ} \mathrm{C}$. The coverslips were mounted on cardboard and exposed, along with concentration standards, to Kodak SB5 $x$-ray film for 10 days in an $x$-ray cassette. The film was developed in an industrial Processing $X$-ray Developer. If the images did not have a median optical density between 0.5 and 0.9 , the sections were exposed again for a longer or shorter period. When images of suitable darkness had been obtained, the sections were stained with thionin (see Gallistel, 1981, for more details).

Choice of an index of localized alterations in activity. The autoradiographic images were analyzed at the Biotechnology Resource Center at Drexel University. The system is described by Gallistel et al. (1982b) and Gallistel and Tretiak (1985), who also discuss the reasons for preferring a normalized index of activation, rather than estimates of local glucose utilization, when the purpose of an experiment is to detect discretely localized changes in metabolically coupled functional activity. In the course of the present work, we evaluated normalized indices of activation for robushess and sensitivity. An index of activation is robust if it is unaffected by deliberately produced differences in the overall darkness of images. It is sensitive if the withinanimal and between-animal SDs in the values obtained for a structure are small relative to the difference between the darkest (most active) and lightest (least active) structures. The indices we evaluated were: (1) the gray-matter to white-matter concentration ratio (the ratio of the mean isotope concentration in a structure to the mean concentration in the white matter); (2) several indices based on $z$-scores; and (3) the mean relative optical density (ROD). The ROD of a pixel (a digitized 50- $\mu \mathrm{m}$ square spot in an image) is its darkness rank relative to the other pixels in the image. An ROD of 85 means that the pixel is darker than $85 \%$ of the pixels in the image. The mean ROD for a structure is the average of the RODs of the pixels in that structure.

To evaluate robustness, we exposed sections from a control animal for three different durations $-5,10$, and 20 days. For each index, we made two determinations of its mean value in each of three structures at each of three exposure durations. This yielded a 3 (structures) $\times 3$ (exposure durations) analysis of variance (ANOVA) for each index, with two observations per cell. The three structures, seen in a section through the posterior diencephalon, were the medial geniculate (a very active structure), the optic tract (one of the lightest structures), and the premammillary nucleus (intermediate activity). An index was robust only if the ANOVA showed no significant effect of exposure duration. Only the mean ROD showed no effect of exposure duration. This robustness is to be expected because rank order is invariant under any monotone transformation.

The ROD also showed the greatest sensitivity; its within-cell error (the square root of the within-cell variance) was $5.6 \%$ of the difference between the means for the darkest and lightest structures. However, this SD reflects only the within animal (between section) variance. To evaluate the sensitivity of the indices in between group comparisons, we turned to the data from the self-stimulation group. In level 2 of our analysis, there is ipsilateral activation of the ventromedial diagonal band of Broca in every section (3) animal) from all five animals (see Fig. 3). We computed the group mean and the associated (between animal) SD for this structure on the stimulated and unstimulated sides. For comparison, we computed the mean and SDs for the lateral half of the septum, a relatively light area, which is not activated by the stimulation. This yielded 4 means and associated SDs $(2$ structures $\times 2$ sides). For the ROD, the average SD was $16 \%$ of the difference between the smallest and largest means; for the concentration ratio, it was $26 \%$; for the other indices, it was still worse. To demonstrate the importance of this difference in sensitivity, we did a $t$-test for the significance of the stimulatedunstimulated difference in compartment " $b$ " of level 2 (see Fig. 1), in which we deliberately did not partial out the between-animal variance (deliberately did not use a paired comparisons test). The difference was significant with 
the ROD statistic, but not with the other statistics. We concluded that the ROD was the most sensitive and robust of the normalized statistics so far suggested, and we used it in our subsequent analyses.

Selection and delineation of structures to be analyzed. We first examined the autoradiographs from the stimulated animals, using color windows to highlight differences between the stimulated and unstimulated sides of the brain. A color window colors all pixels whose gray values (digitized darkness) fall within a user-selected range. The color window on the Drexel system is specified by its lower (darker) threshold which is controlled by a joystick, and its width (interval from lower to upper threshold), which is increased or decreased by keystrokes. The operator can sweep windows of various widths rapidly over the image. Side-side differences in activation yicld asymmetries in coloration at some positions of the color window.

We then drew up a list of structures to be given a quantitative analysis. The list included the structures in which the preliminary inspection had revealed effects, plus areas that make a substantial contribution of descending myelinated fibers to the MFB, plus areas that receive a strong dopaminergic innervation via the MFB. We found that we could cover all the structures we wished to analyze by working at four coronal leveis and analyzing three sections at each level. The levels and the structures analyzed at each level are shown in Figure 1.

The structures were delineated on the histological image of the original section after aligning it with the autoradiographic image. The autoradiographic image stored in memory was displayed on the monitor and outlined by the computer. The operator switched the source of the display to the video camera while retaining the outline on the monitor, and positioned the section, which had been stained following the autoradiography, within the outline of the autoradiograph. The operator outlined the structures, following written drawing rules, which were worked out arnong the authors and the assistants who worked on the image analysis, with the aim of ensuring reproducible delineations. The rules (available upon request) emphasized the following of unmistakable contours where these existed, and, where clear contours were not present, the tracing of straight or nearly straight lines between welldefined reference points. When the structures had been outlined, the outline was superimposed on the autoradiographic image. The operator placed the cursor inside each outline in turn and requested quantification. The computer printed out the mean and SD of the pixel RODs along with an identifying label supplied by the operator. We believe that care taken in the objective delineation of the structures to be quantified is important in achieving reproducible, operator-independent results. Defining structures only with reference to the autoradiographic image and specifying them by name rather than by published outline allows a wide latitude for interinvestigator differences.

Statistical treatment. The design of the experiment yielded a 5 -factor ANOVA for each coronal level, with 2 nested factors. Sections were nested within Animals, and Animals within Conditions. The unnested factors were Condition, Side (of the brain), and Structure. Since ROD is a proportion and cannot be normally distributed at values close to 100 , the arcsin transformation was used. The analysis focused on three series of planned comparisons. To evaluate effects of dopamine receptor blockade on the metabolic activity of each structure, the bilateral average for the two pimozide-treated groups (PS and $\mathrm{PO}$ ) was compared to the corresponding average for the three groups injected with the vehicle alone (SS, OS, and C). To evaluate the bilateral effects of stimulation on each structure, the bilateral average for the three stimulated groups (SS, OS, and PS) was compared to the average for the two unstimulated groups ( $P O$ and $\mathrm{C}$ ). The denominator in these $\mathrm{F}$ ratios was the mean square deviation for Animal within Condition for that structure. To measure unilateral effects of stimulation, the average side-side difference in each structure for the stimulated groups (the right (the stimulated side) minus the left (the unstimulated side) in the SS, OS, and PS groups) was compared to the corresponding average in the unstimulated groups (PO and $C$ ). The denominator in these $F$ ratios was the mean square deviation for the Animal $\times$ Side interaction for a structure. We had planned also to compare the two groups receiving experimenter-administered stimulation (PS and OS) to the self-stimulating group (SS). However, where effects of stimulation were seen, differences between OS and PS were as large or larger than their differences with SS, so the comparison was dropped. In view of both the large number of statistical comparisons made and the fact that each ROD measure contributed to three different comparisons, we adopted a stringent criterion of significance, $p<0.01$.

\section{Results: Experiment I}

Quantitative. There was no detectable activating effect of stimulation at level 1 , at and just anterior to the genu of the corpus callosum, nor at more anterior levels. None of the side-side compar- isons is significant at this level (Table l), nor does inspection of the bilateral data from stimulated and unstimulated groups in Table ॥ suggest a bilateral effect of stimulation. This replicates earlier findings (Yadin et al., 1983). It is also consistent with the finding that unilaterai ablation of the forebrain has no discernible effect on the substrate for MFB stimulation (Stellar et al., 1982). It appears that the reward pathway - the projection system that carries the rewarding signal from the electrode to the point where its rewarding effect is realized-lies almost entirely posterior and ventral to the genu of the corpus callosum.

Reward-blocking doses of pimozide $(0.75 \mathrm{mg} / \mathrm{kg})$ activated the caudate (Table II, levels 1 and 2) but had only a weak and unreliable effect on the accumbens (Table $\|$, level 1 ; the significance level was $p<0.05$ ) and had no significant effect on the medial frontal cortex or the olfactory tubercle, although these structures also receive strong dopaminergic innervation (Lindvall and Bjorklund, 1974). The effect on the caudate is seen in both drug-treated groups (PS and $\mathrm{PO})$ at both anterior levels. It probably reflects the fact that acute neuroleptic administration increases the firing rate of nigrostriatal neurons (Bunney, 1984).

At level 2, just anterior to the anterior commissure, ipsilateral activating effects of stimulation are strong and reliable but are only in more medial structures, structures lying within $1 \mathrm{~mm}$ of the midline. There is no activation of the MFB proper at this level, which lies laterally, in the horizontal limb of the diagonal band (as delineated in the atlas of Nieuwenhuys et al., 1982). The medial structures showing activation at this level include compartment " $b$ " in the atlas of Nieuwenhuys et al. (1982) (see Fig. 1, for depiction) and the ventral half of the vertical limb of the diagonal band (VDB in Fig. 1). There is less strong and less reliable activation in the more dorsal part of the vertical limb of the diagonal band, in what we term the medial septum. This area is not the medial septum proper, which, at this level, is a very thin nuclear area extending only about $0.2 \mathrm{~mm}$ to either side of the midline; rather it is the medial half of the general septal area. Again, the finding of strong activation in these ventral and medial portions of the diagonal band replicates earlier findings (Yadin et al., 1983). There is no evidence of a bilateral effect of stimulation. At level 3, the strongest activation is compartment " $c$ " in the Nieuwenhuys et al. (1982) atlas of the MFB.

The side-side comparison for the bed nucleus of the stria terminalis and the medial preoptic area did not yield $F$ ratios that satisfied our criterion of significance. However, the mean side-side difference exceeds the SE of the mean difference by a factor of more than 2.5 in every stimulated group (and none of the unstimulated groups), suggesting the presence of a weak but reliable effect. This led us to do a nonparametric analysis of these data. In the bed nucleus, the ROD was higher on the stimulated side in 41 of the 45 sections, with the other 4 sections yielding equal RODs on both sides. In 15 of 15 subjecls, at least 2 of 3 sections showed greater activation on the stimulated (right) side. Only 5 of 10 subjects in the unstimulated groups satisfied this criterion. The difference in the proportions of animals satisfying this criterion is significant at beyond the 0.01 level by Fisher's exact probability; therefore, we have listed this effect as significant in Table I. The medial preoptic data present a similar picture, the relative frequencies being 15:0 in the stimulated groups and $4: 6$ in the unstimulated.

There were no significant effects of reward-blocking doses of pimozide at this level in the structures we measured. We did not measure the caudate, having sampled it at the two more anterior levels.

At level 4, a midhypothalamic level, about 0.5 to $1.0 \mathrm{~mm}$ anterior to the stimulating electrode, there was strong and reliable activation of the MFB. In an attempt to see whether there was any clear localization within the MFB, we divided it into 3 rather arbitrary compartments - a dorsolateral third, a dorsomedial third, and a ventral third (see Fig. 1). The activation of all three compartments was significant at beyond the 0.001 level.

At this level was found the only significant bilateral effect of the 
[Level 1(Interaural $10.7 \mathrm{~mm})$ ]
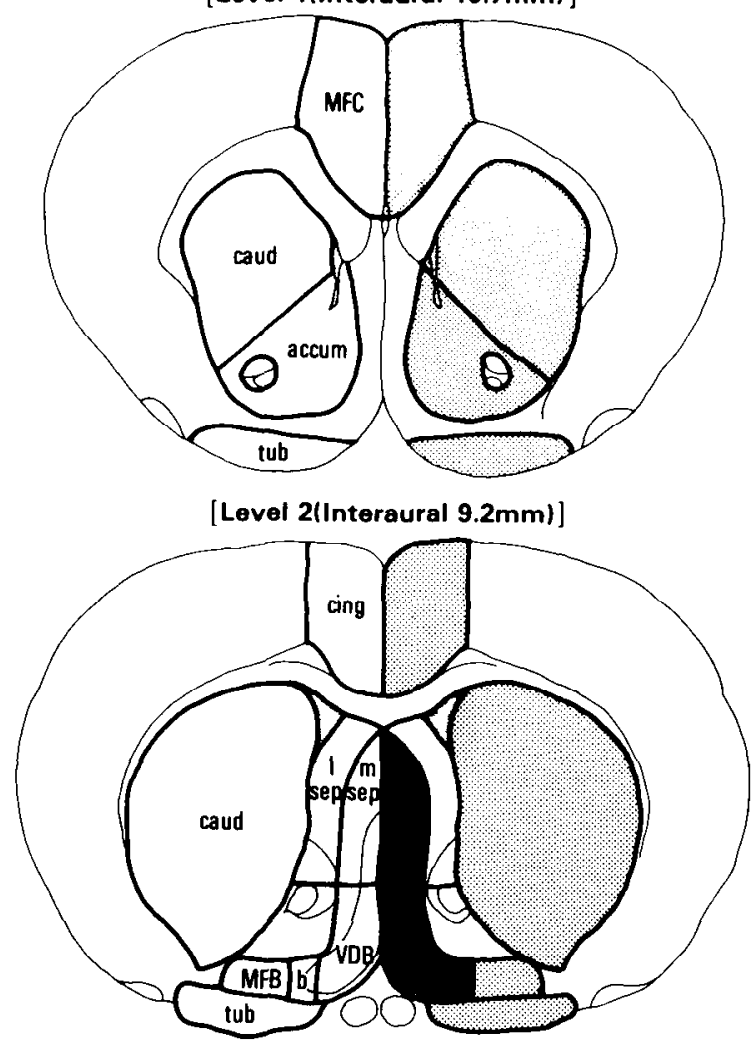

[Level 3(Interaural $8.2 \mathrm{~mm}$ )]

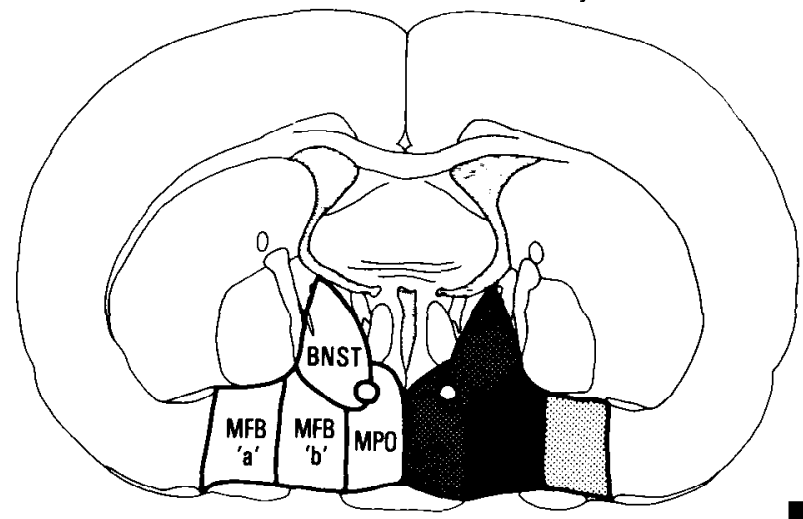

[Level $4($ Interaural $5.2 \mathrm{~mm})$ ]

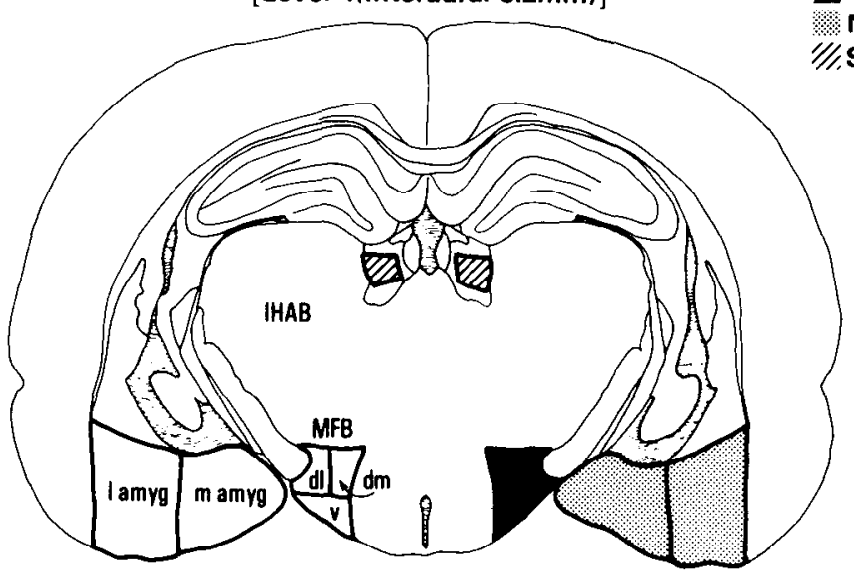

Figure 1. Drawings of coronal sections of the rat brain showing the levels, and the structures given a quantitative analysis. The effects of unilateral rewarding stimulation of the right posterior MFB are shown by the shading. "Strong effects" were significant at the 0.01 level or beyond in the ANOVA; "weaker effects" attained this level of significance only in a post hoc nonparametric analysis. For the effects of the pimozide, see Table II. The drawings are based on the Paxinos and Watson (1982) atlas; the distances anterior to the interaural line refer to their plates. accum, nucleus accumbens; $b$, compartment " $\mathrm{b}$ " in the Nieuwenhuys et al. (1982) atlas of the MFB; caud, caudate; $B N S T$, bed nucleus of the stria terminalis; cing, cingulate cortex; dl MFB, dorsolateral MFB; $d m$ MFB, dorsomedial MFB; / amyg, lateral half of the amygdaloid complex; I hab, lateral habenula; I sep, lateral half of the septal area; $m$ amyg, medial half of the amygdaloid complex; MFB, medial forebrain bundle, as represented in the atlas of Nieuwenhuys et al.; MFBa, compartment "a" of the MFB in the Nieuwenhuys et al. atlas; MFBc, compartment " $c$ " in that atlas; MFC, medial frontal cortex; MPO, medial preoptic area; $m$ sep, medial half of the septal area; tub, olfactory tubercle; $V D B$, vertical limb of the diagonal band of Broca; $v$ $M F B$, ventral MFB.
Strong effect Weaker effect No effect "Suppression 
TABLE I

Mean side-side difference in ROD

\begin{tabular}{|c|c|c|c|c|c|c|}
\hline & \multicolumn{5}{|c|}{ Right (= stimulated)-Left (= unstimulated) } & \multirow{3}{*}{$\begin{array}{c}\text { Comparison } \\
\text { (Stimulated } \\
\text { vs. } \\
\text { unstimulated) }\end{array}$} \\
\hline & \multicolumn{3}{|c|}{ Stimulated groups } & \multicolumn{2}{|c|}{ Unstimulated groups } & \\
\hline & $\mathrm{SS}^{\mathrm{a}}$ & OS & PS & $c$ & $\mathrm{PO}$ & \\
\hline \multicolumn{7}{|l|}{ Level 1} \\
\hline $\mathrm{MFC}^{0}$ & $-1.7 \pm 2.9^{c}$ & $-1.8 \pm 2.4$ & $-2.3 \pm 2.0$ & $-5.2 \pm 4.4$ & $1.9 \pm 3.9$ & $\mathrm{NS}^{\alpha}$ \\
\hline caud. & $0.5 \pm 1.0$ & $-3.2 \pm 2.1$ & $-2.6 \pm 4.5$ & $-4.7 \pm 3.1$ & $3.1 \pm 1.4$ & NS \\
\hline accum. & $3.3 \pm 2.1$ & $-0.3 \pm 1.6$ & $0.1 \pm 2.0$ & $2.5 \pm 2.7$ & $-0.5 \pm 2.1$ & NS \\
\hline tub. & $3.3 \pm 4.2$ & $2.5 \pm 1.7$ & $-1.3 \pm 2.2$ & $6.7 \pm 4.3$ & $-4.9 \pm 3.8$ & NS \\
\hline \multicolumn{7}{|l|}{ Level 2} \\
\hline caud. & $-4.1 \pm 1.9$ & $-5.6 \pm 3.2$ & $-1.8 \pm 1.5$ & $-4.3 \pm 1.9$ & $-3.2 \pm 2.8$ & NS \\
\hline tub. & $1.7 \pm 2.3$ & $0.5 \pm 2.2$ & $-0.8 \pm 1.2$ & $-0.1 \pm 3.9$ & $-1.2 \pm 2.4$ & NS \\
\hline cing. & $0.0 \pm 2.6$ & $-3.1 \pm 3.0$ & $-0.6 \pm 0.9$ & $-1.2 \pm 5.2$ & $-0.2 \pm 1.9$ & NS \\
\hline MFB & $1.5 \pm 2.8$ & $4.8 \pm 1.7$ & $-4.3 \pm 2.8$ & $-6.6 \pm 3.7$ & $-1.3 \pm 0.8$ & NS \\
\hline "b" & $11.9 \pm 2.3$ & $11.5 \pm 3.7$ & $8.6 \pm 4.0$ & $-5.3 \pm 3.6$ & $-2.6 \pm 1.5$ & $\ll 0.001$ \\
\hline VDB & $15.0 \pm 3.3$ & $5.1 \pm 1.9$ & $12.0 \pm 1.3$ & $-2.9 \pm 2.5$ & $-0.9+1.2$ & $\ll 0.001$ \\
\hline m sep. & $7.6 \pm 2.5$ & $2.2 \pm 0.6$ & $8.9 \pm 2.8$ & $1.3 \pm 2.4$ & $-0.1 \pm 0.5$ & $<0.01$ \\
\hline I sep. & $0.7 \pm 1.2$ & $0.1 \pm 0.8$ & $4.2 \pm 1.3$ & $-1.9 \pm 2.6$ & $-3.2 \pm 1.3$ & NS \\
\hline \multicolumn{7}{|l|}{ Level 3} \\
\hline BNST & $5.5 \pm 1.4$ & $3.3 \pm 0.3$ & $9.7 \pm 4.6$ & $0.2 \pm 0.6$ & $4.1 \pm 5.0$ & $<0.01^{\mathrm{np}}$ \\
\hline MPO & $4.7 \pm 2.0$ & $2.7 \pm 0.8$ & $11.0 \pm 4.2$ & $-0.8 \pm 4.4$ & $-0.6 \pm 1.7$ & $<0.01^{n p}$ \\
\hline MFBa & $-1.3 \pm 4.6$ & $7.1 \pm 1.7$ & $2.3 \pm 3.6$ & $-3.1 \pm 3.8$ & $-7.1 \pm 8.4$ & NS \\
\hline MFBC & $14.9 \pm 3.0$ & $10.2 \pm 1.8$ & $19.1 \pm 5.2$ & $5.2 \pm 5.8$ & $-2.8 \pm 5.6$ & $<0.005$ \\
\hline \multicolumn{7}{|l|}{ Level 4} \\
\hline I hab. & $-4.8 \pm 1.8$ & $-1.2 \pm 3.4$ & $-3.1 \pm 2.2$ & $-7.1 \pm 4.1$ & $1.9 \pm 2.6$ & NS \\
\hline$\vee \mathrm{M} \Gamma \mathrm{B}$ & $14.5 \pm 6.0$ & $1.0 \pm 2.9$ & $17.7 \pm 6.0$ & $-4.5 \pm 2.7$ & $-3.5 \pm 2.1$ & $<0.001$ \\
\hline dl MFB & $8.1 \pm 3.8$ & $9.9 \pm 3.2$ & $6.4 \pm 3.5$ & $-7.7 \pm 1.6$ & $-3.9 \pm 1.4$ & $\ll 0.001$ \\
\hline $\mathrm{dm}$ MFB & $14.9 \pm 4.2$ & $7.8 \pm 1.3$ & $7.6 \pm 1.6$ & $-2.2 \pm 2.3$ & $-3.1 \pm 2.3$ & $\ll 0.001$ \\
\hline I amyg. & $-2.7 \pm 2.4$ & $0.4 \pm 1.9$ & $3.5 \pm 4.4$ & $-7.8 \pm 4.9$ & $-6.4 \pm 2.3$ & NS \\
\hline m amyg. & $0.7 \pm 1.4$ & $-0.7 \pm 4.0$ & $-0.3 \pm 3.1$ & $-0.9 \pm 2.5$ & $0.3 \pm 1.5$ & NS \\
\hline
\end{tabular}

${ }^{a}$ SS, self-stimulating group; OS, experimenter stimulated; PS, pimozide treated and experimenter stimulated; $\mathrm{C}$, control; PO, pimozide treated, with no stimulation.

${ }^{D}$ For the abbreviations of structure names, see the legend to Figure 1.

${ }^{c}$ Mean \pm SE.

${ }^{d} \mathrm{NS}$, not significant $(p>0.01) ;{ }^{\mathrm{np}}$, by nonparametric analysis.

unilateral stimulation, a significant suppression of metabolic activity in the lateral two-thirds of the lateral habenula. The only effect of pimozide at this level was a very strong activation of the lateral habenula.

Foci of activation. Since a major purpose of this work is to pinpoint areas that may repay electrophysiological investigation, we used color-windows to highlight the major foci of activation at each level. This analysis allowed us to see whether the focus of activation varied from animal to animal. The operator outlined landmarks and structures of interest, working with the aligned histological image, then recalling the autoradiographic image and adjusting the limits of a color window to highlight the focus of activation. The colored pixels within an outlined area were then read into the graphics image (the black on white image created by outlining), creating a stippling effect within the outlined area. The half-tone autoradiographic image was then suppressed, and the stippled graphics image was photographed or printed out on a high-resolution dot-matrix printer.

We first used this analysis to verify the conclusion that the stimulation had no unilateral activating effects in the caudate, the accumbens, the olfactory tubercle, and the medial frontal cortex. There might exist a small focus of activation within these areas that was not picked up in our quantification of the structures as wholes. In Figure 2, each of these four structures has been stippled by color windows chosen to stipple in the highest 10 to $30 \%$ of the pixels in a structure. In our experience, a window that stipples in that percentage of the pixels in a structure will reliably pick out a focus of activity. We cannot discern any consistent asymmetry in the stippling in Figure 2.

In Figure 3, we set the stippling window to pick out the focus of activation within the vertical limb of the diagonal band. The outline of the area within which the stippling routine was bilaterally applied has been retained on the unstimulated side of the images, but suppressed on the stimulated side, so that it is not confounded with the stippling itself. There is always a focus of activation in and around the nucleus of the diagonal band. In some images, a second focus is seen more dorsally.

Figure 4 shows the focus of activation in compartment " $c$ " of the MFB. It appears to be slightly dorsal to the region in which Swanson and Cowan (1979) found the peak concentration of fibers following an injection of tritiated proline into the medial mid-dorsoventral portion of the nucleus of the diagonal band (compare Fig. 4 with Fig. 8C in Swanson and Cowan, 1979, and Fig. 9-3 in Veening et al., 1982). Perhaps injections covering more of the nucleus would shift the peak concentration in this direction.

Figure 5 shows the foci of activation in the MFB at an anterior hypothalamic level, midway between level 3 and level 4, sufficiently far in front of the stimulating electrode so that the activation reflects conducted activation, not activation produced by current spread This level corresponds to level 5 in the atlas of Nieuwenhuys et al. (1982; Fig. 8). In about half the animals, there was a focus of activation just lateral to the vertical bisector of the bundle and slightly ventral to the horizontal bisector, in an area that corresponds approximately to the highest density of descending fibers from the nucleus of the diagonal band (compare the foci of activation in 1SS, 2SS, 3SS, 4SS, 4PS and 5PS with the plot of fiber concentrations at level 5 in Fig. 9 of Veening et al., 1982). In other animals, the focus lay elsewhere, including in and around the fornix (2PS and 3PS in Fig. 5). It does not appear from this analysis that the activated 
TABLE ॥

Bilateral mean RODs

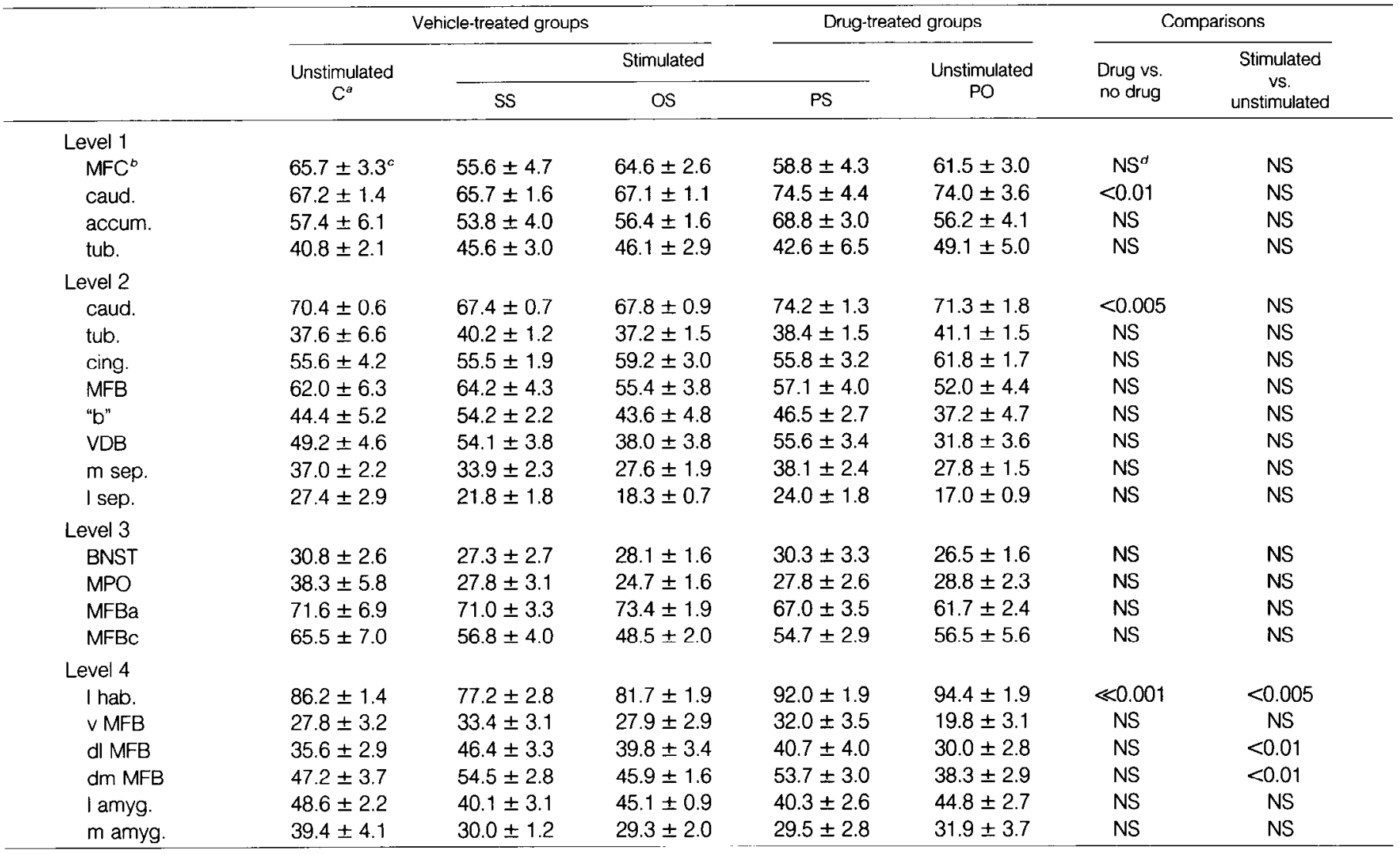

${ }^{a} \mathrm{C}$, control; SS, self-stimulating group; OS, experimenter stimulated; PS, pimozide treated and experimenter stimulated; $\mathrm{PO}$, pimozide treated, with no stimulation.

${ }^{D}$ For the abbreviations of structure names, see the legend to Figure 1.

${ }^{c}$ Mean \pm SE.

${ }^{a} \mathrm{NS}$, not significant $(\rho>0.01)$.

projection system necessarily follows any one position within the MFB. It does appear, however, that descending fibers from the nucleus of the diagonal band are often, if not always, activated.

As reported previously (Yadin et al., 1983), the activation extends back to the more medial portions of $A 9$ and also $A 10$, on the border of the interpeduncular nucleus (Fig. 6). Within the anterior ventral tegmentum, the peak activation is always immediately ventromedial to the medial end of the medial lemniscus. We have not so far detected any reliable effects posterior to the interpeduncular nucleus, but a full quantitative analysis of the posterior midbrain has yet to be done.

\section{Discussion: Experiment I}

When care is taken to use parameters of stimulation that produce a just submaximal rewarding effect, the areas activated by rewarding stimulation of the MFB are a small subset of the areas in which, on anatomical grounds, one might have expected activation. The major efferent projections from the substantia nigra and from the ventral tegmental area ascend in the MFB to innervate a variety of forebrain regions, including the caudate; the accumbens; the olfactory tubercle; the central, medial, and lateral nuclei of the amygdala; the lateral septal nucleus; the medial frontal cortex; the cingulate cortex; and the entorhinal area; in addition to the nucleus of the diagonal band and the bed nucleus of the stria terminalis (Beckstead et al., 1979; Simon et al., 1979; Swanson, 1982). Only the last two terminal fields show detectable activation. Areas making substantial contributions of descending fibers to the MFB include the olfactory tubercle, the nucleus of the lateral olfactory tract, the magnocellular preoptic nucleus, the central nucleus of the amygdala, the ventral ondopyri form nucleus, the accumbens, the caudate, the lateral septal nucleus, and the lateral preoptic area, in addition to the bed nucleus of the stria terminalis and the nucleus of the diagonal band (Veening et al., 1982). Again, only the last two areas of origin show significant activation.

The autoradiographic effects of reward-blocking doses of pimozide are also limited. The clear effects of pimozide at these doses $(0.75 \mathrm{mg} / \mathrm{kg})$ are seen only in the caudate. The clear activation of the caudate (and less certain activation of the accumbens) probably reflects the activating effect of acute neuroleptic administration upon dopaminergic projection systems (Bunney, 1984). That such activation is not seen in consequence of the rewarding stimulation suggests that if the stimulation activates these systems at all, then it does so more weakly than acute neuroleptic administration.

The most striking effect of pirnozide is in the lateral two-thirds of the lateral habenula, where it produces intense activation. This is the more interesting in that: (1) the rewarding stimulation bilateraily suppresses lateral habenular activity; and (2) amphetamine, which enhances the rewarding efficacy of MFB stimulation (Gallistel and Karras, 1984), suppresses activity in the lateral habenula (McCulloch et al., 1980). This led Gomita and Gallistel (1982) to conjecture that both these drugs exert their effect on the rewarding efficacy of stimulation by way of the lateral habenula. This conjecture has not yet been tested by the appropriate lesion or knife-cut experiment.

To our surprise, none of the most prominent dopaminergic terminal areas - the accumbens, the caudate, the medial frontal cortex (the "pregenual" terminal field in the terminology of Lindvall et al., 1978), 


\section{Level 1}

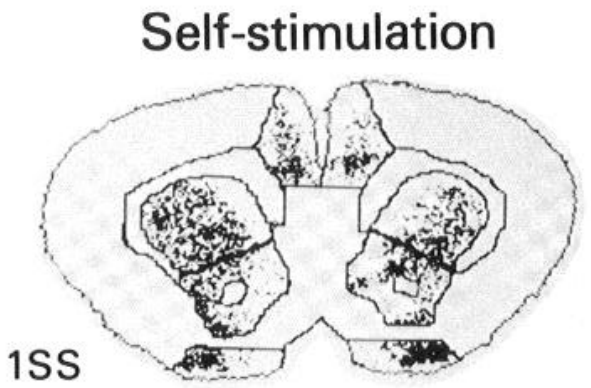

\section{Pimozide and stimulation}
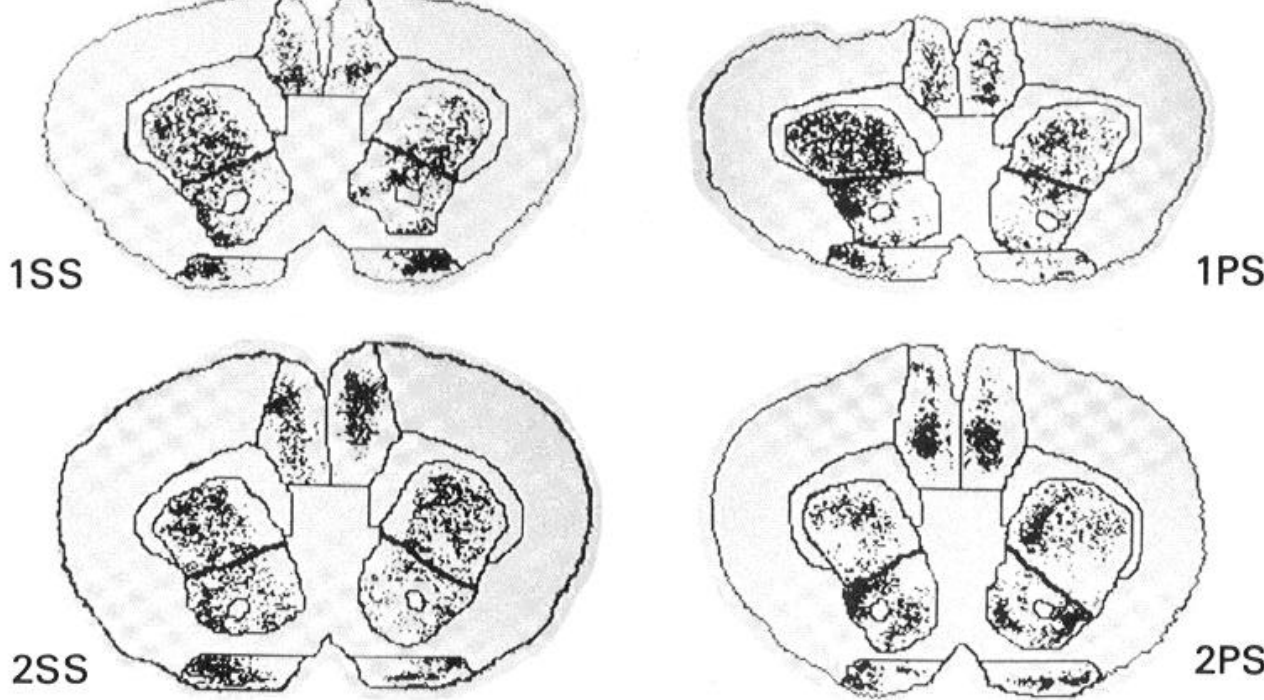

Figure 2. Drawings stippled by color windows, from level-1 sections in self-stimulating animals and in animals treated with pimozide and given stimulation by the experimenter. Anterior to the genu of the corpus callosum, the color windows do not reveal any consistent unilateral activation.
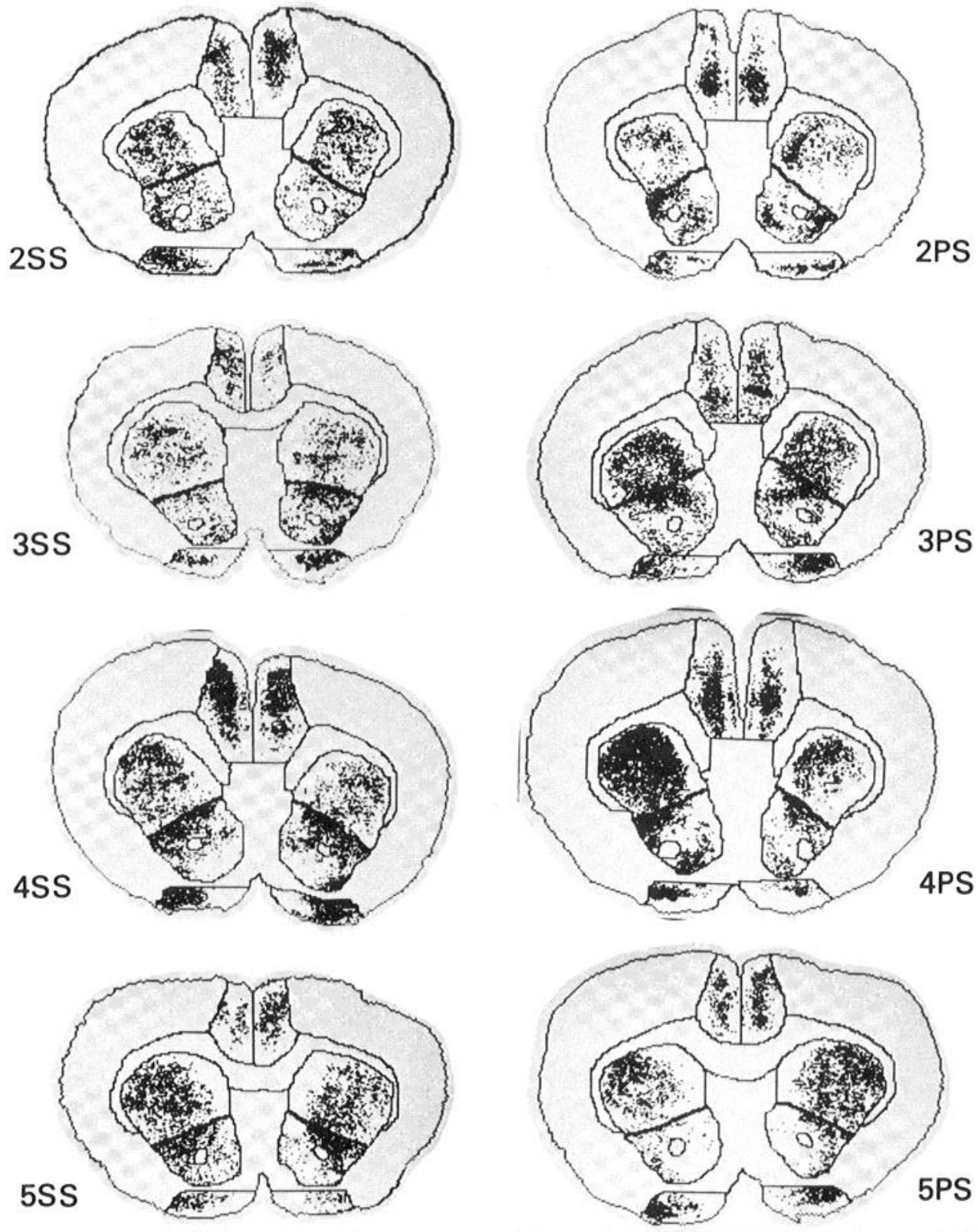

the cingulate cortex (the "supragenual" terminal field), and the olfactory tubercle-is detectably activated by the stimulation. If these projections were strongly activated electrophysiologically, then one would expect this to eventuate in strong metabolic activation as well. Projections composed of small unmyelinated axons should incur a greater metabolic debt from a given level of firing than projections comprised of thicker, myelinated axons. However, the limits of the 2DG technique are not well understood; it is possible that for some reason it fails to pick up activation in these and other projections. To check this possibility, we did a supplementary experiment in which we tried to activate these ascending dopaminergic projection systems by varying the parameters and site of stimulation.

\section{Experiment II}

The purpose of this experiment was to determine whether other projection systems in the MFB would be activated if we used different stimulating 


\section{Level 2}

\section{Self-stimulation}
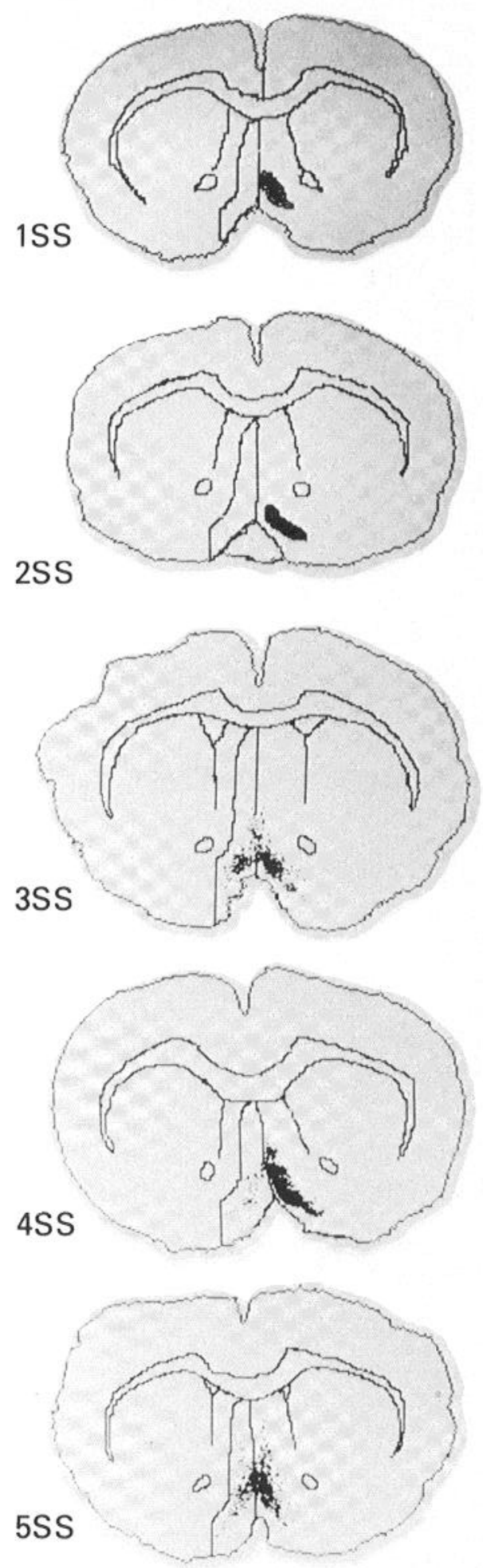

\section{Pimozide and stimulation}
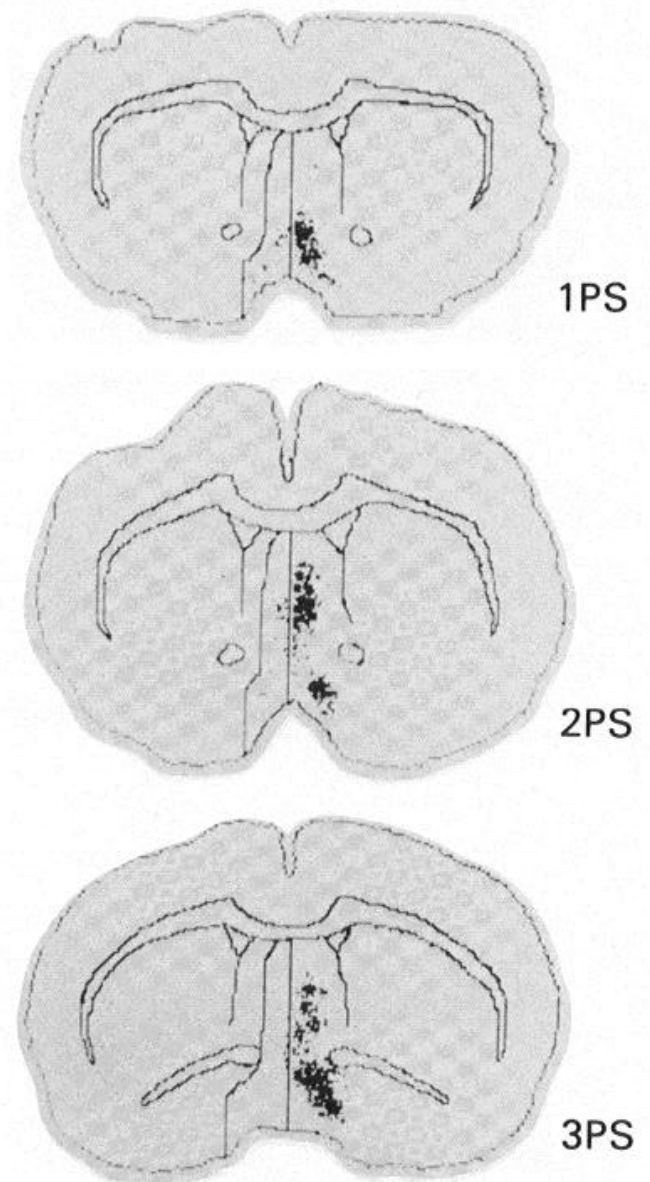

Figure 3. Drawings stippled by color windows, from level 2 sections. Note the consistent focus of stimulation-produced activation in the nucleus of the diagonal band of Broca, and, in some animals (2PS and $3 P S$ ) a second focus higher in the vertical limb of the diagonal band.

\section{PS}
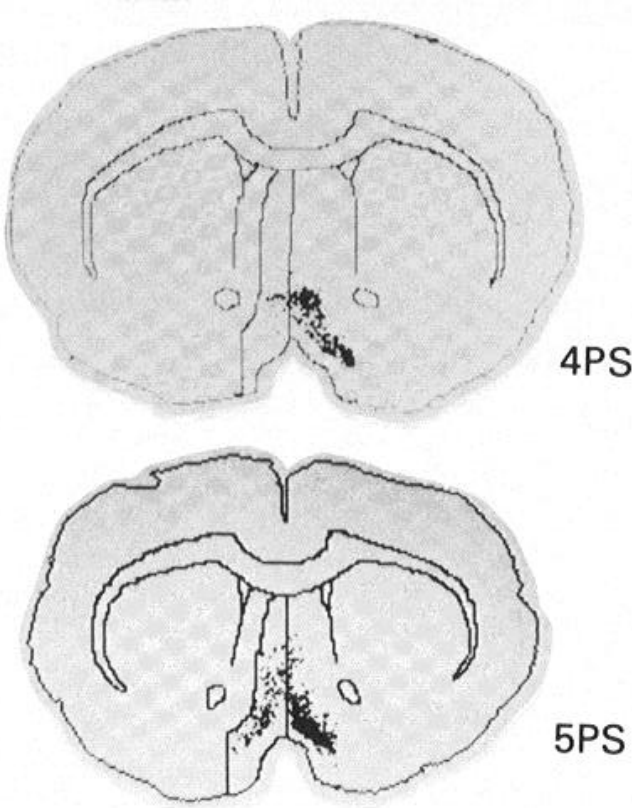

parameters or a different site of stimulation, and more particularly, to determine whether the 2DG technique could show activation of dopaminergic projection systems when the parameters and/or the site of stimulation made activation of these systems more probable.

\section{Methods}

We prepared rats with chronically implanted monopolar stimulating electrodes as in the previous experiment. In five rats, the electrodes were

implanted in the MFB at the same posterior hypothalamic level used in the previous experiment. In five additional rats, the electrodes were aimed at the pars compacta of the substantia nigra (area A9; coordinates: -5.3 from bregma, 1.9 to 2.3 lateral, $7.7 \mathrm{~mm}$ below the level skull surface). The rats were of the same strain, sex, and general weight as those in the previous experiment.

The rats with electrodes in the MFB at the posterior hypothalamic level were trained to press a bar as in the previous experiment. Once they had 


\section{Level 3}

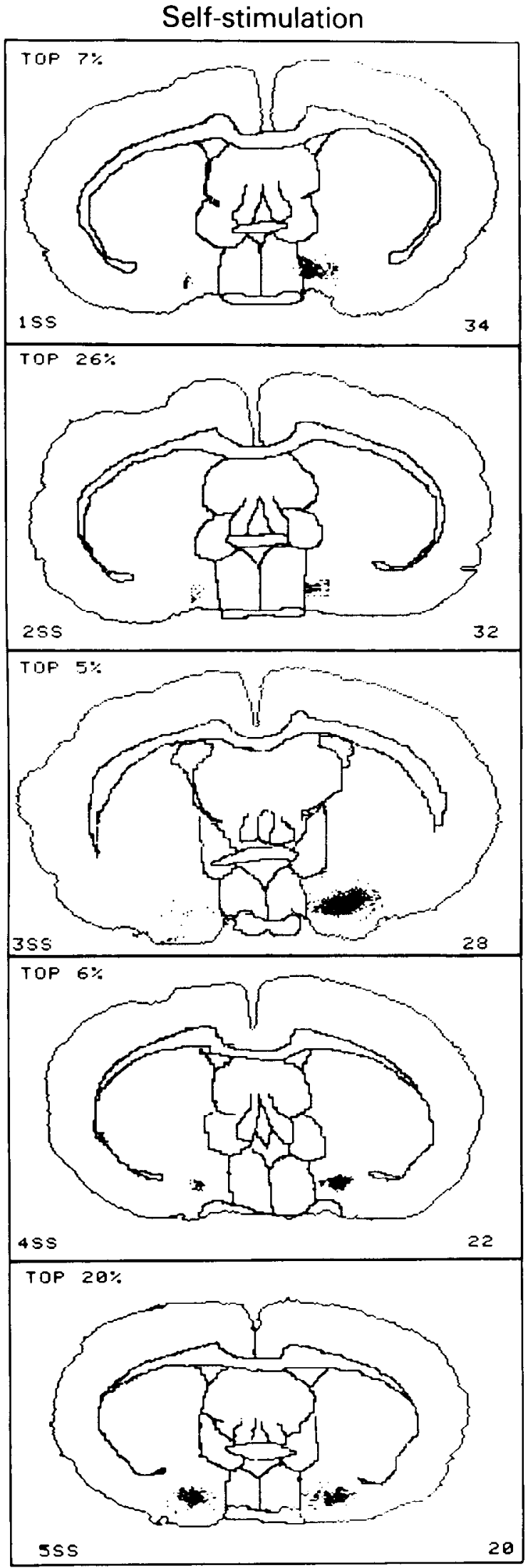

Pimozide and stimulation

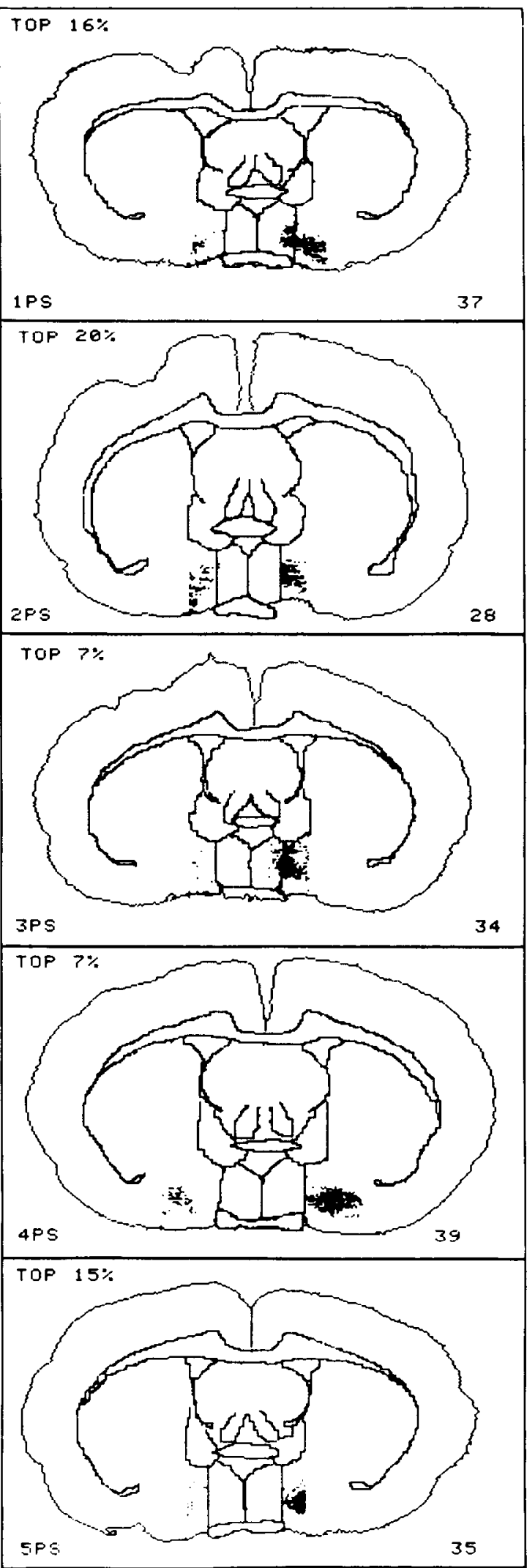

Figure 4. Drawings stippled by color windows, from level 3 sections. Note the focus of activation in compartment $\mathrm{c}$ of the medial torebrain bundle, just lateral to the medial preoptic nucleus. The print-out of the graphics image horizontally elongates the images by about $10 \%$. 


\section{Level $3 \frac{1}{2}$}

\section{Self-stimulation}

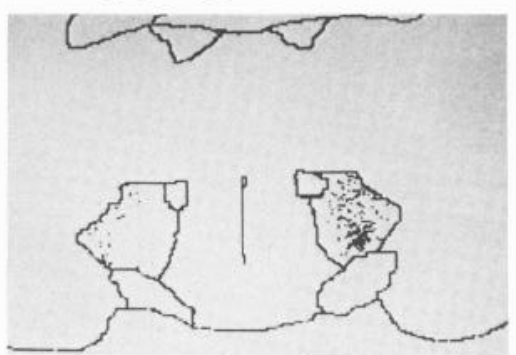

1SS

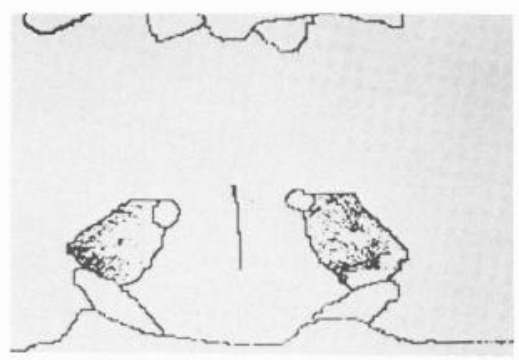

2SS

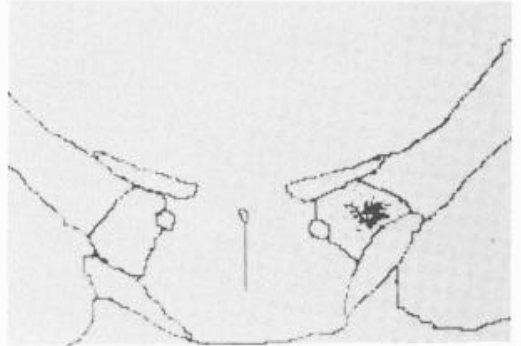

$3 S S$

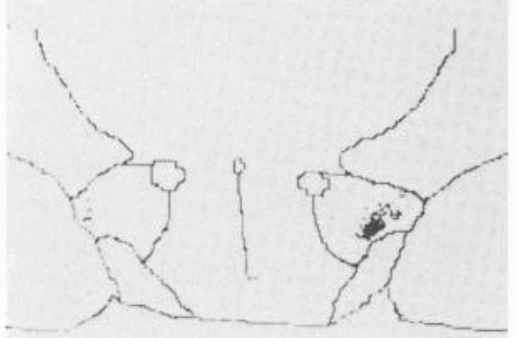

4SS

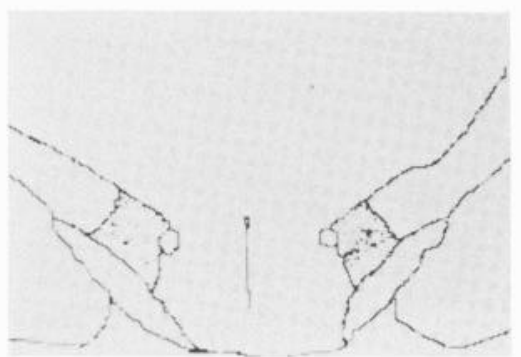

5SS

learned with the standard parameters, the pulse duration was increased to $1.5 \mathrm{msec}$, in the belief that this might recruit unmyelinated projection systems. As before, the rate-intensity function was determined repeatedly. During uptake of the 2DG, these rats self-stimulated at the intensity that produced a rate equal to $75 \%$ of the maximum rate.

\section{Pimozide and stimulation}

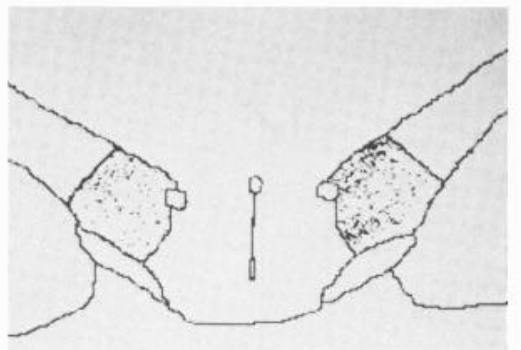

1PS

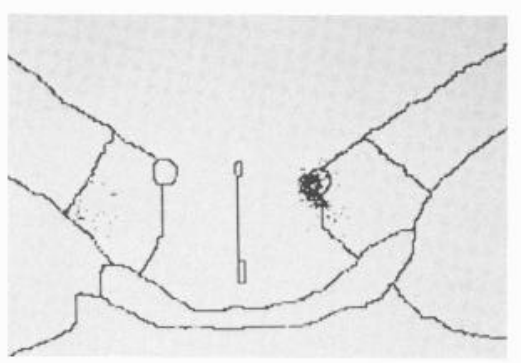

2PS

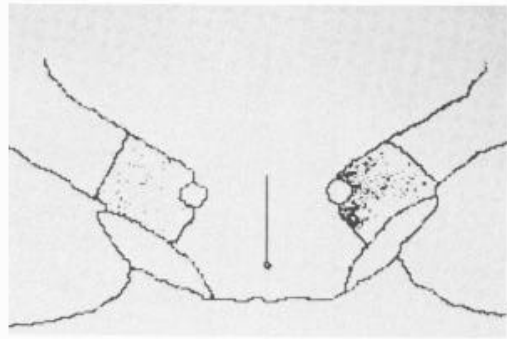

3PS

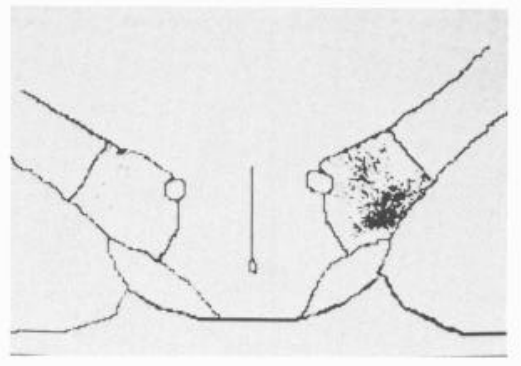

4PS

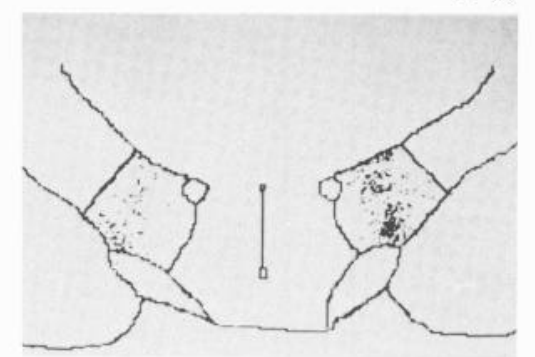

5PS

Figure 5. Drawings from sections at a level midway etween levels 3 and 4 , with the MFB stippled by color indows.

The rats implanted in the substantia nigra (the SN group) were screened for self-stimulation and were tested with various parameters of stimulation to elicit strong turning responses. During 2DG uptake, all of these rats received a 0.5 -sec stimulation train at 400 to $600 \mu \mathrm{A}$, programmed automatically at 1 train/sec, throughout the $45-\mathrm{min}$ period. Other parameters of stimulation were 


\section{Level VTA}
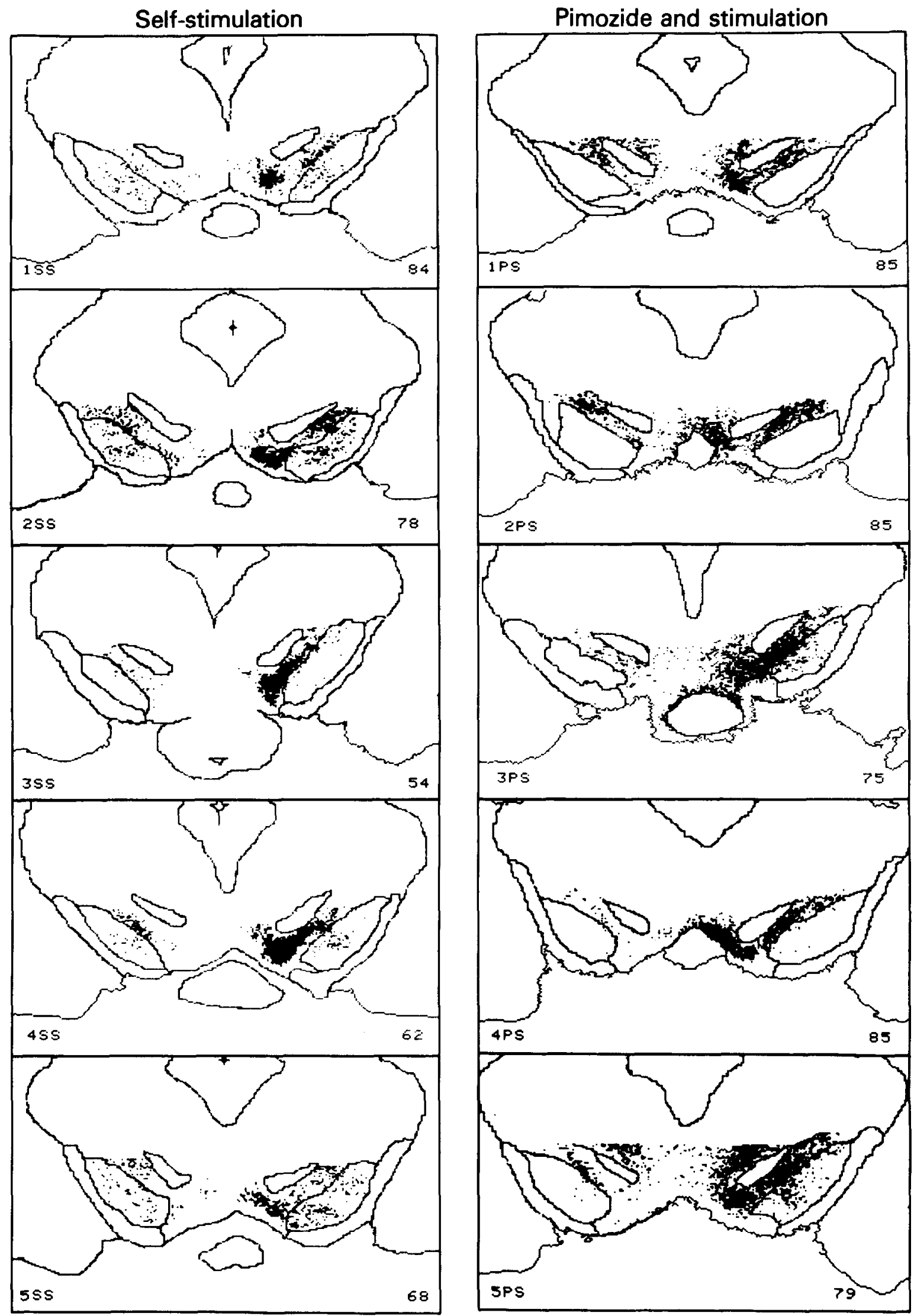

Figure 6 . Drawings from sections between the posterior portion of the mammillary bodies and the interpeduncular nucleus, stippled with color windows in the anterior ventral tegmental area. Note activation in $A 9$ and $A 10$. 
varied to maximize the chance of activating different systems. For four rats, the frequency was 100 pps with the pulse width set at $0.1 \mathrm{msec}, 0.25 \mathrm{msec}$, or $1.5 \mathrm{msec}(2$ rats). The fifth rat was given $0.1 \mathrm{msec}$ pulses at a frequency of 20 pps.

\section{Results: Experiment II}

In three of the five rats self-stimulating with the long pulse durations the pattern of activation was similar to that already reported. In two rats, however, there was, in addition to the pattern already described, strong activation of the mesolimbic projections to the accumbens, the medial frontal cortex, and the suprarhinal cortex. One rat also showed strong activation of the plexiform layer of the olfactory bulb, the anterior and dorsal olfactory nuclei, the amygdaloid complex, the nucleus of the lateral olfactory tract, and the pyriform cortex (Fig. $7 A$ ). In short, it showed strong activation of many of the ascending and descending systems that were not activated in experiment I.

Of the five rats in the SN group, three had electrode tips in the 7ona compacta or zona reticulata of the substantia nigra; the other two tips were just dorsal to the substantia nigra but produced strong autoradiographic activation of its dorsolateral portion. All of these animals were screened for self-stimulation, but only one (SN-4) was positive. In these $\mathrm{SN}$ animals, the caudate nucleus was examined for autoradiographic effects at level 2 of the MFB analysis. Caudate metabolism was elevated on both the stimulated side and the unstimulated side (SN group versus combined SS and OS groups: $\rho<0.01$, for each side). There were marked asymmetries in the strength of caudate activation (Fig. $7 B$ ). Activation was greater on the stimulated side in three animals (Fig. 7B, top three brains), and on the contralateral side in the other two, probably indicating that different systems were activated by different electrode placements and different stimulation parameters.

\section{Discussion: Experiment II}

The results of our second experiment show that our failure to see activation of many of the projection systems in the MFB in the first experiment was not because the 2DG technique is incapable of showing activation of these systems. If these systems had been directly stimulated (therefore strongly activated) in experiment $I$, then this activation would have been apparent in the autoradiographs. These data, therefore, constitute further evidence that ascending catecholaminergic pathways are not the directly stimulated component of the reward pathway.

These results also demonstrate the importance of choosing the site and intensity of stimulation on the basis of behavioral criteria. In most work to date, careful attention has not been paid to the selection of the parameters of stimulation. There has been some tendency to use strong parameters of stimulation in order to produce strong autoradiographic effects. The two experiments together show that this is not necessary. If the purpose of the autoradiography is to identify neural systems likely to be mediating some behavioral effect of the stimulation, then it is counterproductive to use stimulation parameters substantially stronger than those that just suffice to produce a good behavioral effect. In the first experiment, using parameters that just sufficed to produce good self-stimulation, we obtained strong, highly reproducible, but discrete effects. Using still stronger parameters would tend to recruit additional systems, such as those whose activation we have shown in the second experiment, systems irrelevant to the behavioral effect that interests us.

\section{General Discussion}

\section{Activated projections}

In Figure 8, we have assembled the results of our analyses to portray the trajectory of tissue metabolically activated by rewarding stimulation of the posterior MFB. The onset of activation begins in the vertical limb of the diagonal band, with the focus of activation being reliably in and around the nucleus of the diagonal band. There appears to be a second and more diffuse onset in the bed nucleus of the stria terminalis. This may represent fibers passing through this area en route to or from the diagonal band. It may also reflect ascending projections terminating in the bed nucleus. In any event, the most anterior activation is medial, lying for the most part within $1 \mathrm{~mm}$ of the midline. Following the activation posteriorly, one sees it swing out more laterally in the anterior hypothalamus, being most noticeable in compartment "c," the part of the MFB just lateral to the medial preoptic area. This area receives descending fibers from the nucleus of the diagonal band and from the bed nucleus of the stria terminalis (Swanson and Cowan, 1979; Veening et al., 1982). At this level, the medial preoptic area and the bed nucleus are weakly but reliably activated. This may reflect the diffuse presence of activated fibers of passage, or it may indicate that soma of activated descending axons lie in these nuclei, too. By the midhypothalamic level, the activation is found throughout the MFB. Its focus varies from rat to rat, but, more often than not, it lies in compartments "d" and "a." In the posterior hypothalamus, the activation continues to be concentrated in the MFB as the bundle swings medially. Activation appears to end in the ventral tegmental area.

The autoradiographic analysis does not distinguish between re ward-relevant activation and the activation of tissue irrelevant to the rewarding effect of the stimulation. To make that distinction, one must turn to electrophysiological recording, where one may test individual neurons for possession of the quantitative properties revealed by the new quantitative behavioral methods (Shizgal and Rompré, 1985). Also crucial to the identification of the rewardrelevant projection will be knife-cut studies, in which the percentage of damage to the reward-relevant population of fibers is measured behaviorally and correlated with the extent of degeneration seen in various projection systems (Janas and Stellar, 1984). These autoradiographic results provide clear suggestions about where the recording electrodes and cutting knives should first be aimed. The projection that descends from the nucleus of the diagonal band is a prime candidate.

\section{The dopaminergic projection systems}

Our data do not disprove the hypothesis that the major dopaminergic projection systems are activated by rewarding stimulation of the brain at moderate parameters of stimulation. However, they provide no support for this hypothesis. The following considerations seem relevant

There was clear activation of the substantia nigra pars compacta (A9) and of the ventral tegmental area (A10), as can be seen in Figure 6. Both of these areas contain a mixture of dopaminergic and nondopaminergic cell bodies (Guyenet and Aghajanian, 1978), so activation in these areas does not necessarily indicate activation of dopaminergic neurons, nor even activation of terminals ending on the soma and dendrites thereof.

The dopaminergic projections originating in these areas generally have inhibitory effects upon electrophysiological activity in the caudate and accumbens (Bloom et al., 1965; Herz and Zieglganzberger, 1968; Brown and Arbuthnott, 1983), although there is controversy on this point (Bevan et al., 1975; Norcross and Spehlman, 1978). One might conjecture that a decrease in postsynaptic metabolism masked an increase in presynaptic metabolism. On theoretical grounds, this is not likely, because the extent of the metabolic changes produced by changes in electrophysiological activity should be a function of the surface to volume ratio, which will be much higher for the presynaptic tissue than for the postsynaptic tissue We attribute the activation we see to the metabolic deficits incurred by the endings of activated fibers; all of our findings are consistent with this assumption. When we stimulated the substantia nigra directly, we saw strong activation of the caudate (experiment II and Fig. $7 B$ ). When we increased the pulse width in self-stimulating animals, we sometimes observed strong activation of the accumbens and of the prefrontal cortex (Fig. 7A). In these cases at least inhibitory postsynaptic effects did not mask presynaptic activation. 

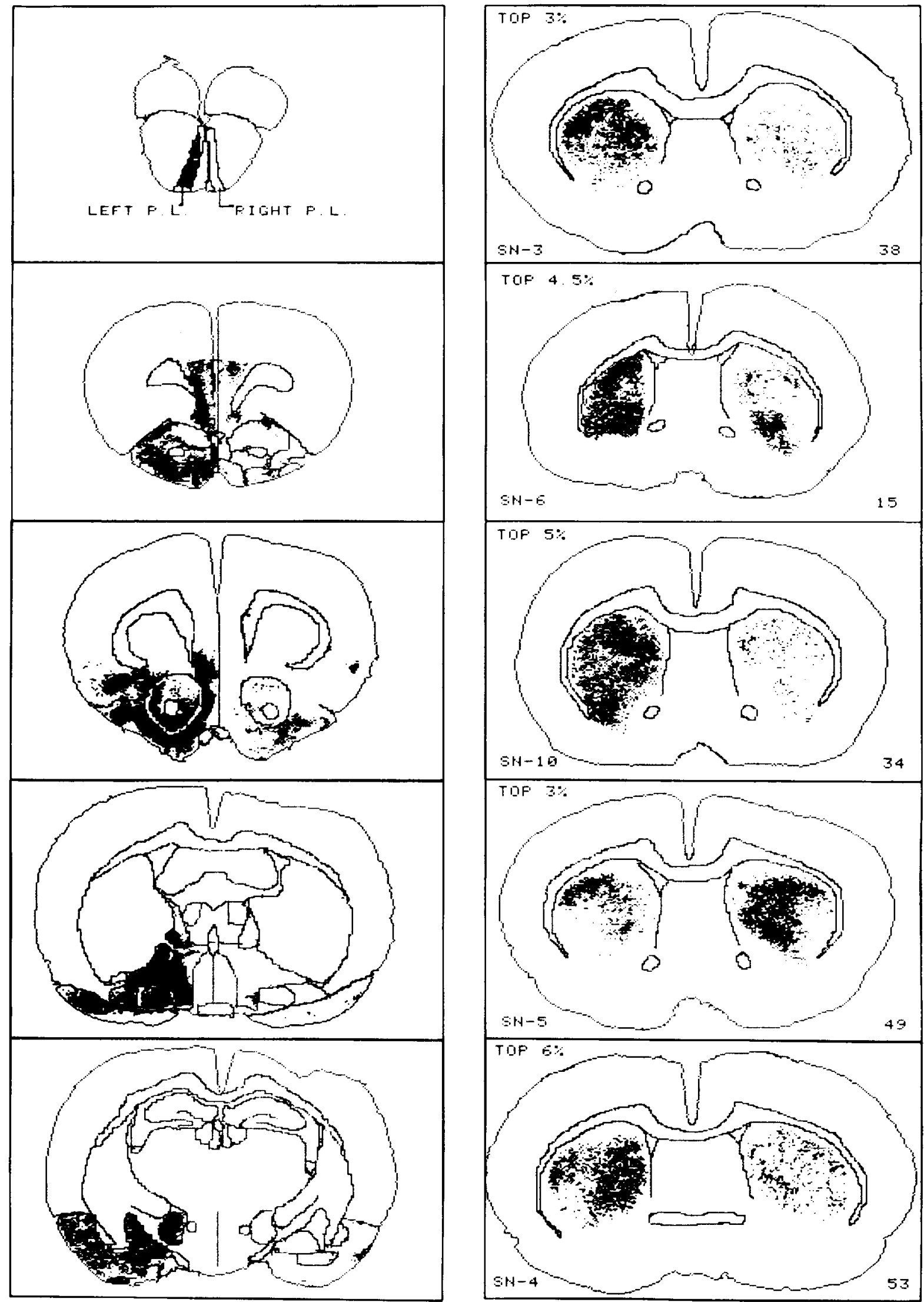

Figure 7. Drawings stippled by color windows to reveal activating effects of long pulse rewarding stimulation of the posterior MFB or turning-producing stimulation of the substantia nigra. $A$, In this rat, self-stimulating for $1.5-\mathrm{msec}$ pulses (100 pps, $100 \mu \mathrm{A}, 0.5-\mathrm{sec}$ train duration, 68 trains/min), there was activation of the plexiform laycr of the olfactory bulb (top); the pregenual dopaminergic projection area (second and third drawings); the anterior, medial, and dorsal olfactory nuclei (second drawing); the ventral accumbens, the suprarhinal cortex, and the olfactory tubercle (third drawing); the amygdaloid complex (third, fourth, and fifth drawings); the nucleus of the lateral olfactory tract (fourth drawing); and the pyriform cortex (drawings 2 to 5 ). $B$, In these five rats with electrodes in the subslantia nigra, one sees strongly asymmetrical activation favoring either the stimulated side (top three drawings) or the contralateral side (bottom two drawings). Both the stimulated side and the unstimulated side were more activated than in rats from the two stimulated, undrugged groups in experiment $\mathrm{I}$. 


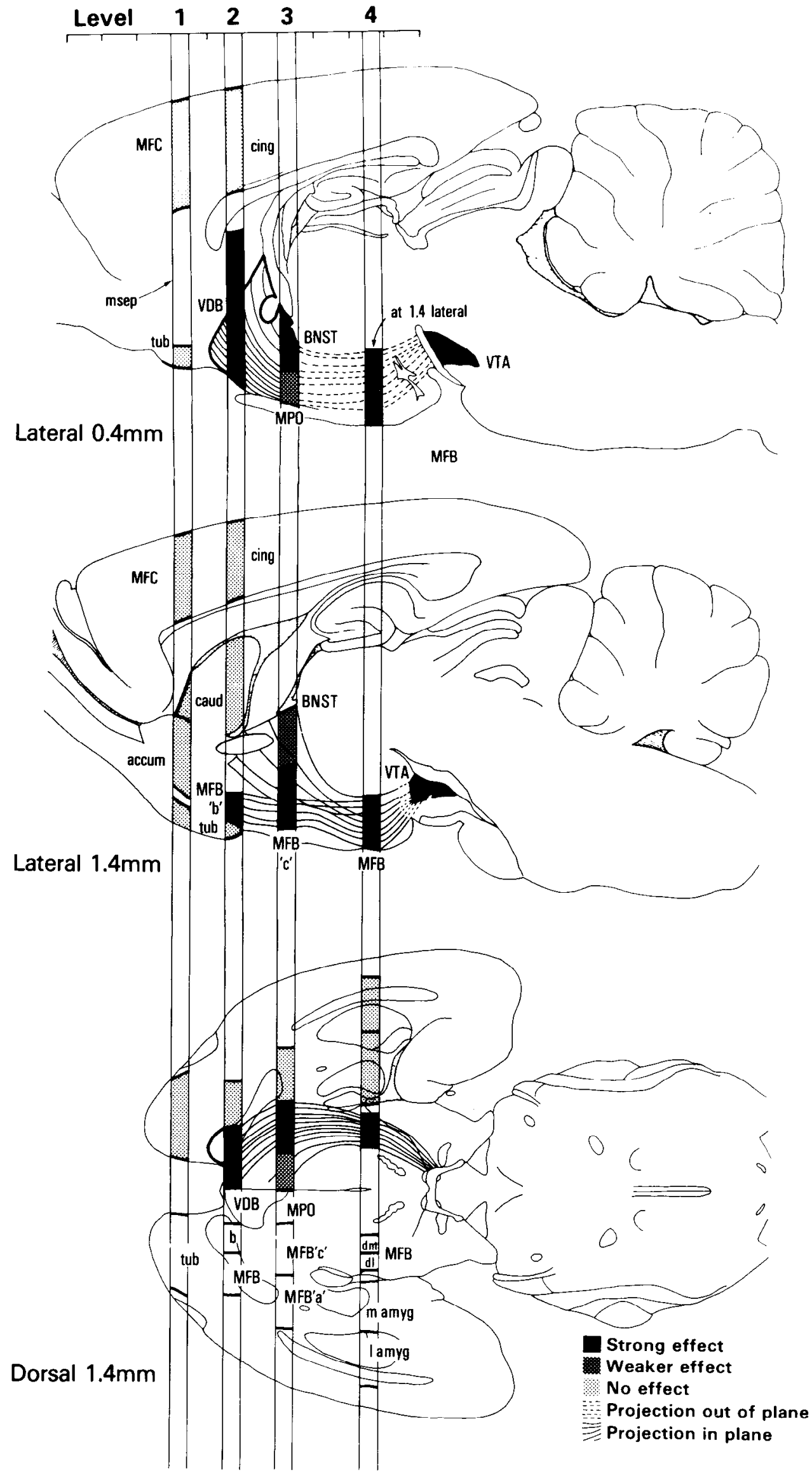

Figure 8. Reconstruction, on sagittal and horizontal sections, of the projection system activated by just submaximal rewarding stimulation of the posterior MFB. The drawings are based on the atlas of Paxinos and Watson (1982); the indicated lateral and dorsal coordinates refer to their plates. Levels 1 to 4 of our quantitative analysis are indicated, and the areas figuring in that analysis are shaded in, to indicate the presence or absence of statistically significant effects of stimulation. "Strong effects" were significant at the 0.01 level or beyond in the ANOVA; "weaker effects" attained this level of significance only in a post hoc nonparametric analysis. 
The dopaminergic projections are composed of small unmyelinated fibers. One might conjecture that the 2DG technique does not reveal changes in the activation of such fibers. On theoretical grounds, the opposite should be true. Because of the high surface to volume ratio and the lack of myelination, a spike should have a higher metabolic cost in a small unmyelinated axon than in a larger myelinated one. The technique shows activation of myelinated pathways; in an earlier experiment, the fornix was inadvertently stimulated in some of our animals, producing dramatic changes in its autoradiographic activation (Gomita and Gallistel, 1982). There is thus every reason to expect that the technique should be sensitive to the activation of the dopaminergic projection systems. Several of our findings appear to confirm this expectation. Direct stimulation of the substantia nigra did activate the caudate (experiment II). There is a nondopaminergic nigrostriatal pathway (Guyenet and Crane, 1981), which might account for this effect. However, in Figure $7 A$, one also sees strong activation of what we take to be part of the mesocortical dopaminergic projection (second panel from top).

It might be argued that transynaptic activation of the dopaminergic projection systems is much milder than the activation we produced by direct stimulation. The dopaminergic neurons are normally silent or fire at low rates ( 2 to 8 spikes/sec; Bunney et al., 1973), although they can be driven one-for-one by 50 - to $100-\mathrm{Hz}$ stimulation (Chiodo and Bunney, 1983). Perhaps the technique does not reveal changes in activity in the range below 10 impulses/sec, the range within which one might expect to find the putative transynaptic effect of rewarding stimulation. Against this is the fact that we detected the effect of a neuroleptic. The maximal effect of acute neuroleptic treatment on the firing of dopaminergic neurons is a doubling of their basal firing rate (Bunney et al., 1973). Our dose of pimozide $(0.75 \mathrm{mg} / \mathrm{kg})$ presumably produced this maximal effect, that is, it increased the average rate of firing from around 5 to around 10 impulses/sec. We assume that the autoradiographic activation produced by pimozide in the caudate reflects this mild increase. If this assumption is correct, then the transynaptic effects of rewarding stimulation, if they exist, must be slight.

It is also possible that the effect of rewarding stimulation on dopaminergic neurons is inhibitory and that the 2DG technique does not reveal a decrease in the already low rate of firing. Against this is the finding (E. Braunstein, S. Rosen, and C. R. Gallistel, manuscript in preparation) that $3 \mathrm{mg} / \mathrm{kg}$ of amphetamine reduces the metabolic activity of the accumbens. This dose strongly reduces the spontaneous activity of dopaminergic neurons (Bunney et al., 1973); we assume the reduced autoradiographic activity reflects the reduced firing in the dopaminergic projection to the accumbens.

All of these arguments are indirect; they do not rule out the possibility of a functionally significant activation of dopaminergic projections by rewarding stimulation. However, in the light of these arguments, one should consider other hypotheses to explain the attenuation by neuroleptics of the rewarding impact of stimulation. Grace and Bunney $(1983$, p. 314) have argued for a "neuromodulatory role for DA function in the striatum, rather than a classical, fastacting neurotransmitter function." It is possible that this neuromodulatory system controls an important aspect of the neural milieu interne and that interference with this function leads to the breakdown of proper functioning in nondopaminergic circuits outside the striatum. This hypothesis would explain why pimozide had no effect on the pathway that was activated by the stimulation. This pathway, which we know from behavioral measurements is not dopaminergic (Gallistel et al., 1981), appears to terminate in the ventral tegmental area, an area that receives substantial projections from the striatum and the accumbens. The hypothesis that disturbed dopaminergic function leads to the breakdown of nondopaminergic function in circuits remote from the dopaminergic terminal fields would also explain the diversity of seemingly unrelated behavioral effects that result from experimental or pathological disturbance of dopaminergic function.

When we have identified the directly stimulated pathway for the rewarding effect, it will be possible to design anatomical and electrophysiological experiments that yield definitive answers to the question whether this pathway does or does not synapse on and activate an ascending dopaminergic projection system. The primary contribution of the present findings is to focus the search for that directly stimulated pathway. Given the profound effects that stimulation of this pathway has on the overall organization of behavior, its identification can hardly fail to further our understanding of the neurophysiological basis of higher behavioral function in mammals.

\section{References}

Beckstead, R. M., V. B. Domesick, and W. J. H. Nauta (1979) Efferent connections of the substantia nigra and ventral togmental area in the rat. Brain Res. 175: 191-217.

Bevan, P., C. M. Bradshaw, and E. Szabadi (1975) Effects of desipramine on neuronal responses to dopamine, noradrenaline, 5-hydroxytryptamine and acetylcholine in the caudate nucleus of the rat. $\mathrm{Br}$. J. Pharmacol. 54: 285-293.

Bloom, F. E., R. Costa, and G. C. Salmoraghi (1965) Anaestesia and the responsiveness of individual neurones of the caudate nucleus of the cat to acetylcholine, norepinephrine and dopamine, administered by microelectrophoresis. J. Pharmacol. Exp. Ther. 150: 244-252.

Brown, J. R., and G. W. Arbuthnott (1983) The electrophysiology of dopamine $\left(D_{2}\right)$ receptors: A study of the action of dopamine on corticostriatal transmission. Neuroscience 10: 349-355.

Bunney, V. A. (1984) Antipsychotic drug effects on the electrical activity of dopaminergic neurons. Trends Neurosci. 7: 212-215.

Bunney, B. S., J. R. Watters, R. H. Roth, and G. K. Aghajanian (1973) Dopaminergic neurons: Effect of antipsychotic drugs and amphetamine on single cell activity. J. Pharmacol. Exp. Ther. 185: 560-571.

Chiodo, L. A., and B. S. Bunney (1983) Typical and atypical neuroleptics: Differential effects of chronic administration on the activity of A9 and A10 midbrain dopamine neurons. J. Neurosci. 3: 1607-1619.

Fouriezos, G., and R. A. Wise (1976) Pimozide-induced extinction of intracranial self-stimulation. Response patterns rule out motor or performance deficits. Brain Res. 103: 377-380.

Franklin, K. B. J. (1978) Catecholamines and self-stimulation: Reward and performance effects dissociated. Pharmacol. Biochem. Behav. 9: 813820.

Gallistel, C. R. (1981) Subcortical stimulation for motivation and reinforcement. In Electrical Slimulation Techmiques, M. M. Patterson and R. Kesner, eds., pp. 141-171, Academic Press, Inc., New York.

Gallistel, C. R., and A. J. Davis (1983) Affinity for the dopamine $D_{2}$ receptor predicts neuroleptic potency in blocking the reinforcing effect of MFB stimulation. Pharmacol. Biochem. Behav. 19: 867-872.

Gallistel, C. R., and D. Karras (1984) Pimozide and amphetamine have opposing effects on the reward summation function. Pharmacol. Biochem. Behav. 20: 73-77.

Gallistel, C. R., and O. Tretiak (1985) Microcomputer systems for analyzing 2-deoxyglucose autoradiographs. In The Microcomputer in Cell and Neurobiology Research, R. R. Mize, ed., Elsevier-North Holland Publishing Co., New York.

Gallistel, C. R., P. Shizgal, and J. S. Yeomans (1981) A portrait of the substrate for self-stimulation. Psychol. Rev. 88: 228-273.

Gallistel, C. R., M. Boytim, Y. Gomita, and L. Klebanoff (1982a) Does pimozide block the reinforcing effect of brain stimulation? Pharmacol. Biochem. Behav. 17: 769-781.

Gallistel, C. R., C. T. Piner, T. O. Allen, N. T. Adler, E. Yadin, and M. Negin (1982b) Computer assisted analysis of 2-DG autoradiographs. Neurosci. Biobehav. Rev. 6: 409-420.

Gomita, Y., and C. R. Gallistel (1982) Effects of reinforcement-blocking doses of pimozide on neural systems driven by rewarding stimulation of the MFB: $A{ }^{14} \mathrm{C}-2$-Deoxyglucose analysis. Pharmacol. Biochem. Behav. 17: $841-845$.

Grace, A. A., and B. S. Bunney (1983) Intracellular and extracellular electrophysiology of nigral dopaminergic neurons. I. Identification and characterization. Neuroscience 10: 301-315.

Guyenet, P. G., and G. K. Aghajanian (1978) Antidromic identification of 
dopaminergic and other output neurons of the rat substantia nigra. Brain Res. 150: 69-84.

Guyenet, P. G., and J. K. Crane (1981) Non-dopaminergic nigrostriatal pathway. Brain Res. 213: 291-305.

Herz, A. and W. Zieglgansberger (1968) The influence of micro-electrophoretically applied biogenic amines, cholinomimetics and procaine on syn aptic excitation in corpus striatum. Int. J. Neuropharmacol. 7: 221-230.

Hoebel, B. G. (1984) Neurotransmitters in the control of feeding and its rewards: Monoamines, opiates, and brain-gut peptides. In Eating and Its Disorders, A. J. Stunkard and E. Steller, eds., pp. 15-38, Raven Press, New York.

Janas, J. and J. R. Stellar (1984) Effect of transections of the medial forebrain bundle on self-stimulation reward. Canadian Psychology 25: Abstr. 243.

König. J. F. R. and R. A. Klippel (1967) The Rat Brain: A Stereotaxic Atlas, Williams \& Wilkins, Baltimore.

Liebman, J. M., and L. L. Butcher (1974) Comparative involvement of dopamine and noradrenaline in rate-free self-stimulation in substantia nigra, lateral hypothalamus, and mesencephalic central gray. Naunyn Schmiedebergs Arch. Pharmacol. 284: 167-194.

Lindvall, O., and A. Bjorklund (1974) The organization of the ascending catecholamine neuron systems in the rat brain as revealed by the glyoxylic acid fluorescence method. Acta Physiol. Scand. (Suppl.) 412: 1-48.

Lindvall, O., A. Bjorklund, and I. Divac (1978) Organization of catecholamine neurons projecting to the frontal cortex in the rat. Brain Res. 142: 1-24.

Lyness, W. H., N. M. Friedle, and K. E. Moore (1979) Destruction of dopaminergic nerve terminals in nucleus accumbens: Effect of $d$-am. phetamine self-administration. Pharmacol. Biochem. Behav. 11: 663-666.

McCulloch, J., H. E. Savaki, and L. Sokoloff (1980) Influence of dopaminergic systems on the lateral habenular nucleus of the rat. Brain Res. 194: 117124.

Nieuwenhuys, R., L. M. G. Geeraedts, and J. G. Veening (1982) The medial forebrain bundie of the rat. I. General introduction. J. Comp. Neurol. 206: $48-81$.

Norcross, K., and R. Spehlman (1978) A quantitative analysis of the excitatory and depressant effects of dopamine on the firing of caudatal neurones: Electrophysiological support for the existence of two distinct dopaminesensitive receptors. Brain Res. 156: 168-174.

Paxinos, G. and C. Watson (1982) The Rat Brain in Stereotaxic Coordinates, Academic Press, Inc., New York.
Pickens, R., R. A. Meisch, and J. Thompson (1978) Drug self-administeration. An analysis of the reinforcing effects of drugs. In Handbook of Pharmacology, L. L. Iversen, S. D. Iversen, and S. H. Snyder, eds., Vol. 12, pp. 1-37, Plenum Press, New York.

Roberts, D. C. S., M. E. Corcoran, and H. C. Fibiger (1977) On the role of asconding catecholaminergic systems in intravenous self-administration of cocaine. Pharmacol. Biochem. Behav. 6: 615-620.

Shizgal, P., and P. -P. Rompré (1985) Electrophysiological characteristics of neurons in forebrain regions implicated in self-stimulation of the medial forebrain bundle in the rat. Brain Res., in press.

Simon, H., M. LeMoal, and A. Calas (1979) Efferents and afferents of the ventral tegmental A10 region studied after local injection of $\left[{ }^{3} \mathrm{H}\right]$-leucine and horseradish peroxidase. Brain Res. 178: 17-40.

Sokoloff, L., M. Reivich, C. Kennedy, and M. Des Rosiers (1977) The ${ }^{14} \mathrm{C}-$ deoxyglucose method for measurement of local cerebral glucose utilization. Theory, procedure, and normal values in the conscious and anesthetized albino rat. J. Neurochem. 28: 897-916.

Stellar, J. R., J. lles, and L. E. Mills (1982) Role of ipsilateral forebrain in lateral hypothalamic stimulation reward in rats. Physiol. Behav. 29: 10891097.

Swanson, L. W. (1982) The projection of the ventral tegmental area and adjacent regions: $A$ combined fluorescent retrograde tracer and immunofluorescence study in the rat. Brain Res. Butl. 9: 321-353.

Swanson, L. W. and W. M. Cowan (1979) The connections of the septal region in the rat. J. Comp. Neurol. 186: 621-656.

Veening, J. G., L. W. Swanson, W. M. Cowan, R. Nieuwenhuys, and L. M G. Geeraedts. (1982) The medial forebrain bundle of the rat. II. An autoradiographic study of the topography of the major descending and ascending components. J. Comp. Neurol. 206: 82-108.

Wise, R. A. (1980) The dopamine synapse and the notion of "pleasure centers" in the brain. Trends Neurosci. 3: 91-95.

Wise, R. A. (1982) Neuroleptics and operant behavior: The anhedonia hypothesis. Behav. Brain Sci. 5: 39-87.

Yadin, E., V. Guarini, and C. R. Gallistel (1983) Unilaterally activated systems in rats self-stimulating at sites in the medial forebrain bundle, medial prefrontal cortex or locus coeruleus. Brain Res. 266: 39-50.

Yokel, R. A. and R. A. Wise (1975) Increased lever pressing for amphetamine after pimozide in rats: Implications for a dopamine theory of reward. Science 187: 547-549. 